REVIEW ARTICLE

\title{
Congenital Uterine Anomalies: Impact on Perinatal Outcomes
}

\author{
Orion Gliozheni ${ }^{1} \oplus$, Elko Gliozheni ${ }^{2}$
}

\begin{abstract}
Congenital anomalies of the female reproductive system are defined as deviations from normal anatomy, and present a diagnostic challenge because of the variety of morphologic presentations. They are the result of abnormal development of the Müllerian ducts during embryogenesis. These anatomic disorders occur frequently and may result from genetic mutation, developmental arrest or acquired defects. Disorders range from congenital absence of the vagina and uterus, to defects in lateral or vertical fusion of the Müllerian ducts. A variety of anatomic defects may also be found in the urinary system. These anomalies are often asymptomatic and unrecognized. The true prevalence of uterine anomalies in the population is unknown. A recent major study indicated the prevalence of uterine anomalies (including minor anomalies, such as hypoplastic or arcuate uteri) about $7-8 \%$ in the normal fertile population and $>25 \%$ in women with recurrent spontaneous abortions. Less than half, have clinical symptoms. Provided there is no obstruction to menstrual flow, these uterine anomalies present few problems in the absence of pregnancy. In the presence of pregnancy there is an increased incidence of miscarriage, poor fetal growth and malpresentation or placental adherence. The risk of spontaneous abortions in this group, during the first-trimester is $28-45 \%$, while in the second-trimester is $5 \%$. There are different uterine anomalies. A complete failure of fusion between the ducts results in a didelphic uterus. A partial failure results in an arcuate or bicornuate uterus. A failure of septal resorption results in variants ranging from a subseptate to a septate uterus. Atresia of one of the paramesonephric ducts results in a unicornuate uterus with a single tube. A differential diagnosis is very important, because of prognosis for reproduction and the choice of the most suitable surgical approach. Women with uterine anomalies are known to have a higher incidence of infertility, pelvic pain, recurrent pregnancy loss, preterm labor, fetal mortality, fetal growth restriction, preterm rupture of membranes, abnormal fetal presentation, retained placenta, and increased cesarean delivery rate. US is often the first imaging modality chosen because of its availability, short scan time, and low cost, several limitations are encountered during imaging. Transvaginal imaging, although superior to the transabdominal approach, may not always be possible, as in young girls or patients with vaginal septa. Detection of uterine anomalies by 3D ultrasound or MRI has really increased the accurate diagnosis of these anomalies. Several studies have examined pregnancy outcomes for each specific uterine anomaly. Women with an arcuate uterus have a similar reproductive outcome to women with a normal uterus. The unicornuate uterus has the poorest overall reproductive outcome, and the septate uterus has an increased miscarriage rate. The didelphic uterus, also has poor obstetrical outcomes. Didelphic, bicornuate, unicornuate, and septate uteri have also lower pregnancy rates in ART.
\end{abstract}

Conclusion: Women with congenital uterine malformation usually have poorer reproductive outcomes and higher incidence of complications during pregnancy and delivery. Early diagnosis and treatment can improve obstetric outcomes.

Keywords: Congenital anomalies, Miscarriage, Mullerian anomalies, Perinatal outcome, Preterm delivery, Uterine anomalies.

Donald School Journal of Ultrasound in Obstetrics and Gynecology (2021): 10.5005/jp-journals-10009-1685

\section{INTRODUCTION}

Congenital malformations of the female genital tract are defined as deviations from normal anatomy resulting from embryological maldevelopment of the Müllerian or paramesonephric ducts. These anatomic disorders occur frequently and may result from genetic mutation, developmental arrest, or acquired defects. Disorders range from congenital absence of the vagina and uterus, to defects in lateral or vertical fusion of the Müllerian ducts. A variety of anatomic defects may also be found in the urinary system. These anomalies are often asymptomatic and unrecognized. Less than half have clinical symptoms. Provided there is no obstruction to menstrual flow, uterine anomalies presents few problems in the absence of pregnancy.

Women with uterine anomalies are known to have a higher incidence of infertility, pelvic pain, recurrent pregnancy loss (RPL), preterm labor $(\mathrm{PL})$, fetal mortality, intrauterine growth retardation (IUGR), preterm rupture of membranes, abnormal fetal presentation, retained placenta, and increased cesarean delivery (C/D rate). Müllerian defects are also associated with renal anomalies in $30-50 \%$ of cases, ranging from renal agenesis and severe hypoplasia to ectopic or duplicate uterus.

The true prevalence of congenital Müllerian anomalies, of which uterine malformations constitute the majority, is unknown.

\footnotetext{
1,2 Department of Obstetrics and Gynecology, University of Medicine of Tirana, Albania
}

Corresponding Author: Orion Gliozheni, Department of Obstetrics and Gynecology, University of Medicine of Tirana, Albania, Phone: +355 682029313, e-mail: gliozheniorion@gmail.com

How to cite this article: Gliozheni O, Gliozheni E. Congenital Uterine Anomalies: Impact on Perinatal Outcomes. Donald School J Ultrasound Obstet Gynecol 2021;15(1):64-80.

Source of support: Nil

Conflict of interest: None

This varies depending on the population studied and the diagnostic method used. Most cases are diagnosed during pregnancy or a gynecological examination, but in the absence of symptoms, most anomalies go undiagnosed. Different authors give different findings about the prevalence of uterine anomalies, ranging from $0.5 \%$ to $6 \%$ of women. ${ }^{2}$ Chan report $2-4 \%$ in reproductive age women and $5-25 \%$ in women with adverse reproductive outcomes. ${ }^{3}$ Saravelos based on clinical data, 3D US, sonohysterography (SHG), hysteroscopy (HSC), and laparoscopy (LSC) report prevalence $2.4 \%$ in general population, $5.6 \%$ in women with infertility, and $7.1 \%$ in women with RPL. ${ }^{4}$ Cocksedge report the prevalence of uterine 
anomalies (including minor anomalies, such as hypoplastic or arcuate uteri) about $7-8 \%$ in the normal fertile population and, more than $25 \%$ in women with RPL. ${ }^{4}$

Why this conflicting results? Because most part of trials are individual, observational studies or reviews without control groups and they compare outcomes between patients with a normal uterus to all patients with a uterine anomaly, regardless of type, but we know that different anomalies have different impact on reproductive outcomes. Only few authors realized controlled trials to evaluate the association between the different subtypes of uterine anomalies and various reproductive outcomes.

Congenital anomalies of the reproductive system present a diagnostic challenge because of the variety of morphologic presentations. They are the result of abnormal development of the Müllerian ducts during embryogenesis. A correct interpretation of the many congenital anomalies and disorders of development is not possible without some understanding of the embryology of these organs.

\section{EMBRYOLOGY}

In the absence of testosterone and anti-Müllerian hormone (AMH), the development of internal genitalia occurs. The uterus develops from the two paramesonephric ducts (Müllerian ducts) (Fig. 1). ${ }^{5}$ The caudal two-thirds of these ducts give rise to the uterus and the upper third become the fallopian tubes. The development of the uterus is divided into the three following stages (Fig. 2): ${ }^{6}$

- 6-9 weeks: The appearance of Müllerian ducts and their caudal midline fusion and connection with urogenital sinus.

- 10-13 weeks: The upward fusion of the caudal parts of the Müllerian ducts.

- 14-18 weeks: The resorption of the medial septum initially separating the caudal parts of the Müllerian ducts to form the uterovaginal channel as the origin of both uterine cavity and superior two-thirds of the vagina.

The great majority of the uterine malformations can be explained by the failure or arrest of development during these three stages. Failure of development of the Müllerian ducts between 6 th week and 9th week leads to uterine aplasia; failure of the Müllerian ducts fusion between 10th week and 13th week leads to uterine duplications (a complete failure of fusion between the ducts results

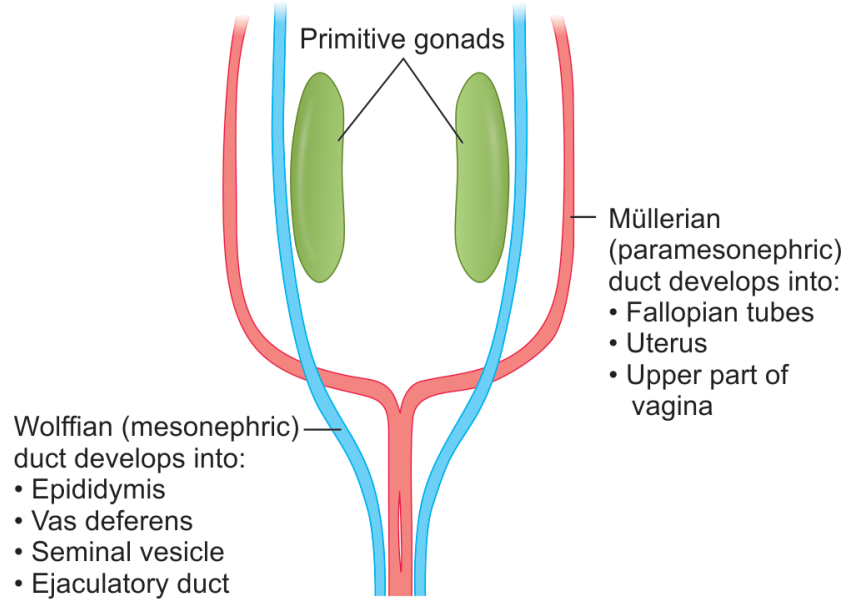

Fig. 1: Müllerian and Wolffian ducts. Source: https://courses.washington. edu/conj/bess/differentiation /differentiation.htm. ${ }^{5}$ in a didelphic uterus and a partial failure of fusion, results in a bicornuate or arcuate uterus); and failure of resorption of the midline septum between 14th week and 18th week leads to septate uterus (the degree of failure leads to variants ranging from a partial to a complete septate uterus). Atresia of one of the paramesonephric ducts results in a unicornuate uterus.

There are also some other important facts. The superior two-thirds of the vagina has the same embryologic origin as the uterus so uterine malformations are often associated with upper vaginal malformations. Genital anomalies are also often associated with urinary tract anomalies (kidneys and urethra) due to close embryological interactions. The uterine malformations are usually not associated with chromosomal or sexual differentiation anomalies.

\section{Uterine Anomalies and Perinatal Outcomes Etiology}

The three main etiologies put forth in order to explain adverse reproductive and pregnancy outcomes in women with uterine anomalies are:

- Diminished muscle mass

- Abnormal uterine blood flow

- Cervical insufficiency.

Diminished muscle mass: The myometrium of congenitally abnormal uteri is thinner than normal, and their mural thickness diminishes as gestation advances (cases of intrapartum uterine ruptures in patients with no prior uterine surgeries have been reported). ${ }^{7,8}$ It is unclear whether this diminished muscle mass plays a role in second trimester abortion, PD and increased rates of CS. For more, high maternal serum alpha-fetoprotein, in the absence of fetal structural abnormalities or multiple pregnancy, has been found to be associated with thin uterine walls, leading some authors to suggest careful inspection of uterine wall contour and thickness in this scenario. .,10 $^{10}$

Diminished uterine blood flow: Caused by absent or abnormal uterine or ovarian vessels, it could potentially explain the IUGR and increased rates of spontaneous abortions in such patients. In a study, in which the vascular configuration of uteri were mapped radiographically, a correlation between anomalous ascending uterine arteries and an increased rate of abortion and IUGR was observed, compared to those patients with normal uterine vasculature. ${ }^{11}$ It is thus possible, that an absent uterine artery on one side could play an important role in the complexities observed in those Müllerian anomalies involving hemiuteri.

Cervical insufficiency: The cervix has been implicated in poor reproductive outcomes, in the setting of uterine malformations, even when there is no anomaly in the cervix itself. Various researchers have postulated an abnormal ratio of muscle fibers to connective tissue in cervix of a uterus with Müllerian anomalies. ${ }^{12,13}$ Several studies have reported a good success in patients with uterine malformations, in which prophylactic cerclage were placed, but no studies, however, have been randomized, and have lacked appropriate controls. ${ }^{14,15}$

\section{Classification}

Due to their significant prevalence and possible impact on the reproductive health of a woman, congenital uterine malformations are a clinical entity and a challenge in the diagnostic and 


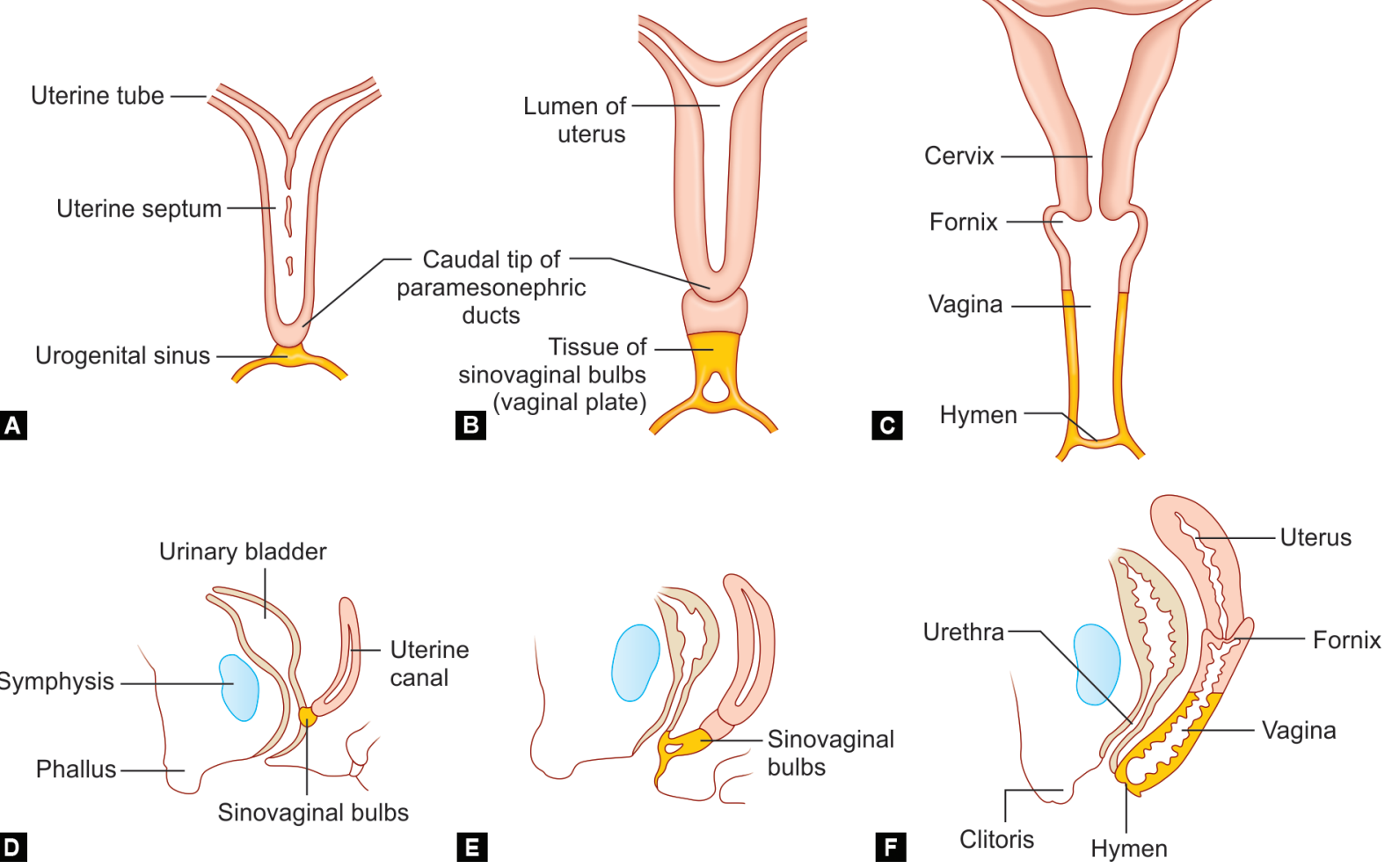

Figs 2A to F: Embryology of uterus and vagina: three stages of development. Source: Hasana DI, Aly Tantawy HI, Shazly SA. Imaging of the uterovaginal anomalies. Egypt J Radiol Nucl Med 2010;41:517-23. ${ }^{6}$

therapeutic decision-making process. An efficient planning of the therapeutic strategy is based on their effective diagnosis and clear categorization. The principle of the classification for uterine anomalies should be followed in which each uterus is validated in function of its possible deviation from the normal parameters.

The uterine malformations are classified according to the embryologic mechanism leading to their formation. Various classification schemes for the female reproductive tract exist, but the most common system was proposed by Buttram ${ }^{16}$ on 1983, adapted on 1988 by the American Fertility Society (AFS), now the American Society of Reproductive Medicine (ASRM) (Table 1, and Fig. 3). Nonetheless, the atypical or intermediate forms of anomalies are difficult to classify. ${ }^{17}$

On 2013, ESHRE and ESGE proposed a new classification system of female genital anomalies. It was designed having mainly clinical orientation and being based on the anatomy of the female genital tract (Fig. 4$)^{18}$

\section{Uterine Hypoplasia/Agenesis}

These anomalies are secondary to partial or complete absence of development of Müllerian ducts. They are frequently associated with renal anomalies. The incidence is 1:4/6,000.2 There are two subclasses in this group:

- Complete bilateral agenesis or complete type I is a rare anomaly and incompatible with life because of associated bilateral renal agenesis.

- Incomplete bilateral agenesis or incomplete type I (also called Mayer-Rokitansky-Küster-Hauser syndrome) is the most
Table 1: Classification of uterine anomalies from American fertility society (AFS)

\begin{tabular}{ll}
\hline Type I & Segmental Müllerian hypoplasia or agenesis \\
& a. Vaginal \\
& b. Cervical \\
c. Uterine fundus & d. Tubal \\
& e. Combined anomalies \\
& Unilateral hypoplasia or agenesis (unicornuate uterus) \\
Type II & a. Rudimentary horn with cavity, communicating to \\
& unicornuate uterus \\
& b. Rudimentary horn with cavity, \\
& noncommunicating to unicornuate uterus \\
& c. Rudimentary horn with no cavity \\
d. Unicornuate uterus without a rudimentary horn & Failure of fusion of Müllerian ducts (Uterus didelphys) \\
Type III & $\begin{array}{l}\text { Partial failure of fusion of Müllerian ducts (Bicornuate } \\
\text { Type IV }\end{array}$ \\
& uterus) \\
a. Complete (division to internal os) & b. Partial \\
Type VI & Arcuate uterus \\
Type VII & Diethylstilbestrol (DES)-related anomalies \\
\hline & a. Complete septation \\
& b. Partial septation
\end{tabular}




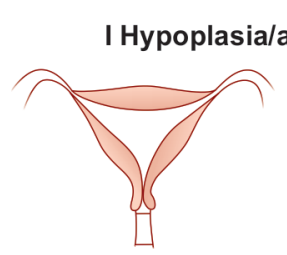

(a) Vaginal

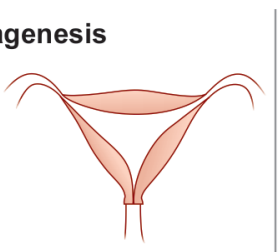

(b) Cervical

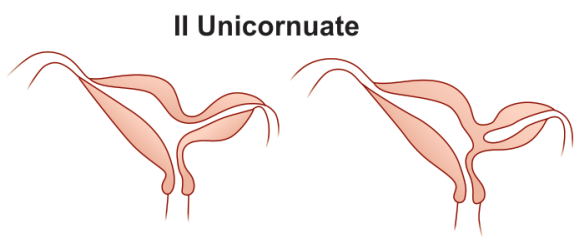

(a) Communicating

(b) Non-communicating
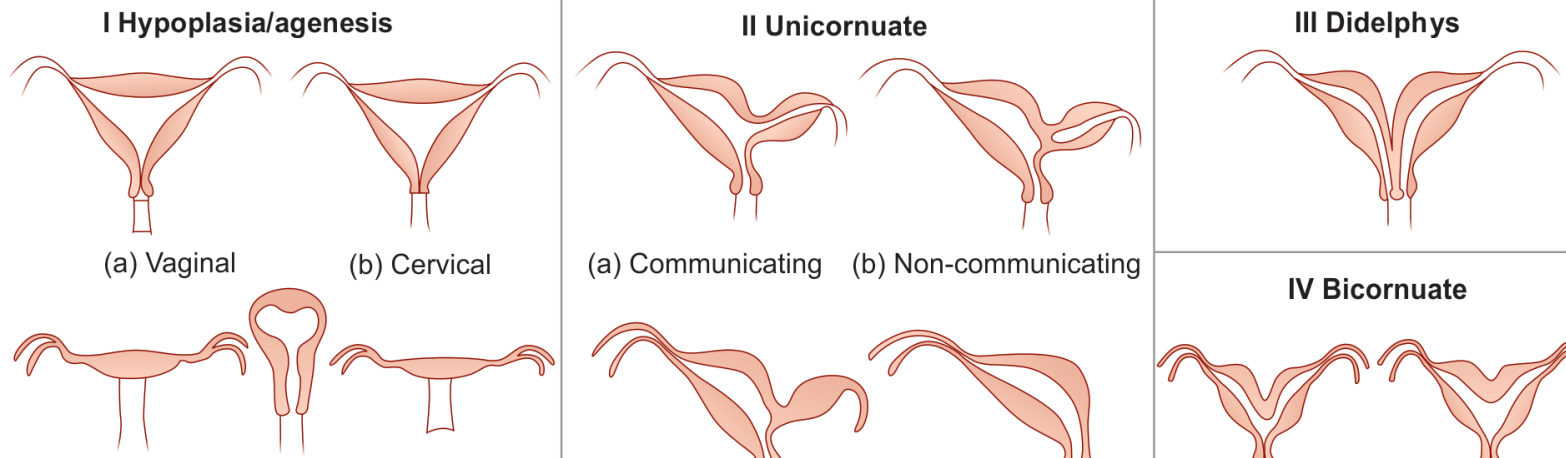

(c) Fundal

(d) Tubal

(e) Combined

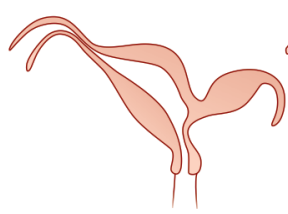

(c) No cavity

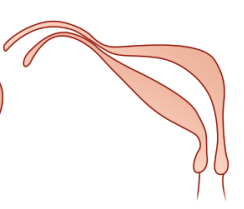

(d) No horn
IV Bicornuate

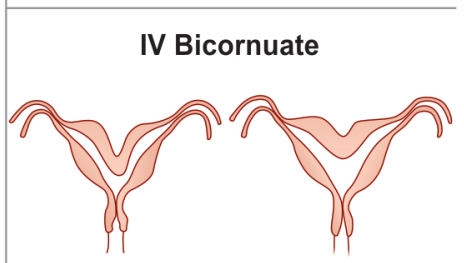

(a) Complete (b) Partial

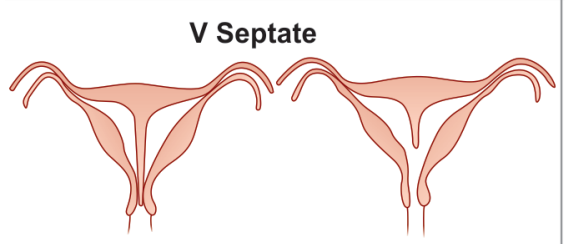

(a) Complete

(b) Partial
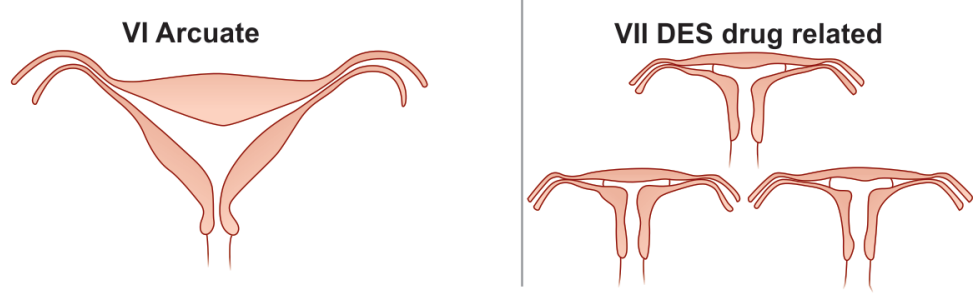

Fig. 3: Classification of uterine anomalies from American Fertility Society (AFS), 1988. Source: The American Fertility Society classifications of adnexal adhesions, distal tubal occlusion, tubal occlusion secondary to tubal ligation, tubal pregnancies, müllerian anomalies and intrauterine adhesions. Fertil Steril. 1988;49:944-955. ${ }^{17}$

common presentation of vaginal atresia or congenital absence of both the uterus and vagina, which is also referred to as Müllerian agenesis or aplasia. This syndrome is characterized by amenorrhea and absence of uterus, cervix, and vagina. Sometimes patients have a shallow vaginal pouch, measuring up to 1.5 inches deep. Most patients have small Müllerian bulbs (rudimentary uterus) without endometrium inside, but in 2-7\% of cases, active endometrium is present, giving cyclic abdominal pain and in those cases, rudimentary uterus has to be removed. ${ }^{19}$ Typically fallopian tubes or a distal portion of them are present and normal ovaries are present because of their separate embryonic origin. Normal ovarian function is associated with normal development of secondary sexual characteristics. Approximately, $15 \%$ of women with uterine agenesis also have defects of the urinary system and $12 \%$ may have scoliosis. ${ }^{20}$

\section{Diagnosis and Management}

Since more women with vaginal atresia have normal external genitalia, this condition does not become apparent until the time of expected menarche. On physical examination, normal breast and pubic hair development are present. The perineum is usually normal, with normal secondary sex signs, the hymenal ring is usually present and beyond the ring, a vaginal dimple or small pouch. A rectoabdominal examination confirms the absence of vagina and uterus and the presence of ovaries. Ultrasound is very useful for excluding or confirming the clinical diagnosis and studying the existing portion of the vaginal canal (Fig. 5A).

Magnetic resonance imaging (MRI) is a more accurate diagnostic tool because we can evaluate the length of the atresia, the presence of cervix or rudimentary uterus, ovaries, and associated urologic abnormalities (Fig. 5B). Laparoscopy is also very useful, especially when ultrasound or MRI cannot give us sufficient information (Fig. 5C). In these patients it is also advisable to study the morphology, volume, and position of the ovaries as these can be entirely absent, present but reduced to fibrous strands or normal but in an ectopic position. Differential diagnosis has to be done between vaginal atresia and transverse vaginal septum. In patients with transverse vaginal septum there is a well-developed vagina and septum separates the lower from the upper part of the vagina. On the other side, the cervix, uterus, fallopian tubes, and ovaries are present and normal. ${ }^{21,22}$

The main treatment goal for most of these women is creation of a functional vagina. This may be accomplished conservatively or surgically. The conservative approaches attempt to progressively invaginate the vaginal dimple with dilators or repeated coitus, in order to enable normal sexual intercourse. Roberts in 2001 and Croak in 2003 report a success rate of $90 \%$ in patients with vaginal atresia, treated with vaginal dilatation techniques. ${ }^{23}$

Surgical procedures are seen as a more immediate solution to creation of a neovagina. Several methods are reported but the method used more commonly by gynecologists is the Mclndoe vaginoplasty. With this technique, a canal is created within the connective tissue between the bladder and rectum. ${ }^{24,25} \mathrm{~A}$ skin graft obtained from the patient's buttock, thigh, or inguinal regional then is wrapped around a soft mould or placed into the newly created vagina to allow epithelialization. Alternatively, other materials such as amniotic membrane, myocutaneous flaps, buccal mucosa, or Ethicon absorbable barrier have been used to line the neovagina. Vaginal stricture can be a significant complication following the Mclndoe procedure, so the vaginal dilatation is mandatory for these patients. ${ }^{26}$ For this reason, surgery may be postponed until a patient has reached a level of maturity for sexual intercourse.

\section{Perinatal Outcomes}

Most patients with this anomaly have at least one normal ovary; so, ovulation induction, retrieval and subsequent 


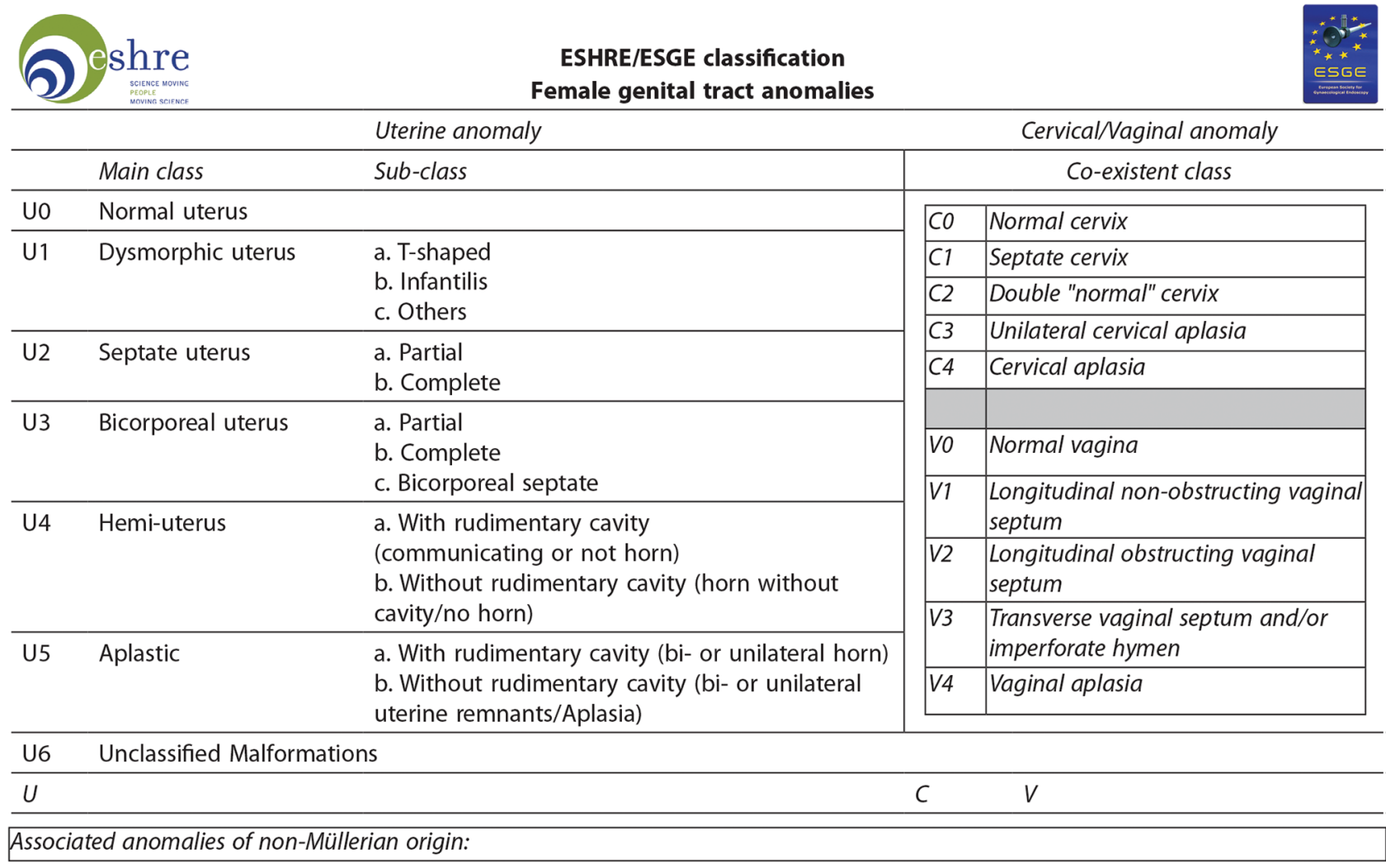

Drawing of the anomaly

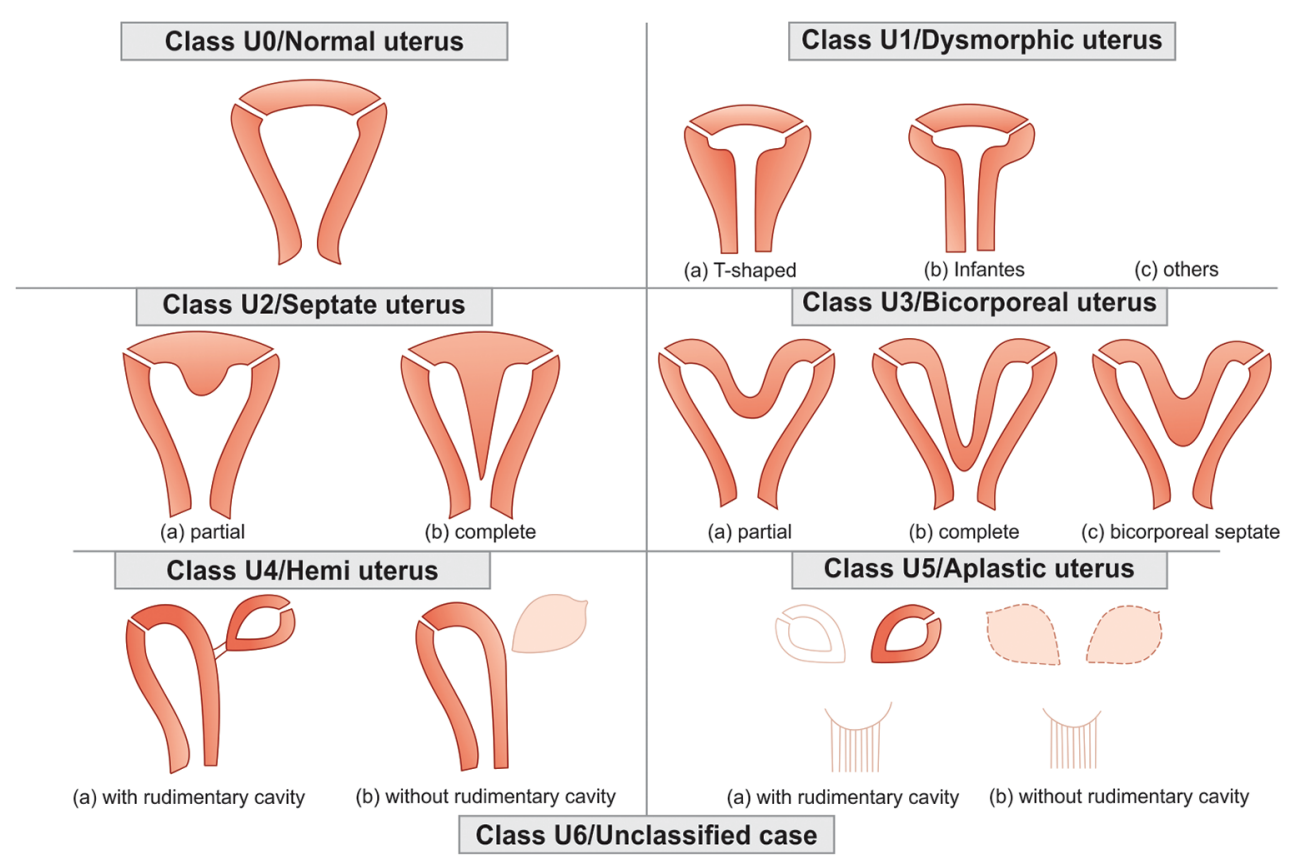

Fig. 4: Classification of uterine malformations [European Society of Human Reproduction and Embryology-European Society of Gynaecological Endoscopy (ESHRE-ESGE) 2013]. Source: Grimbizis GF, Gordts S, Di Spiezio Sardo A, et al. The ESHRE/ESGE consensus on the classification of female genital tract congenital anomalies. Hum Reprod. 2013;28:2032-2044. ${ }^{18}$

transfer to a gestational carrier offer the opportunity for these patients to have genetically related offspring. Uterine transplantation has resulted in live births, but given limited data, this procedure currently is considered experimental and is not widely available. ${ }^{27,28}$ Understanding future fertility options allows young women to understand their possibility for getting pregnant and help them cope with the diagnosis and its implications. 


\section{Unicornuate Uterus}

Arrested development or incomplete development of one of the Müllerian ducts results in a unicornuate uterus. Zanetti reported the incidence of unicornuate uterus as $14 \%$, as diagnosed by hysterosalpingography (HSG), but it was an underestimation because HSG cannot identify noncommunicating rudimentary horn, by far the most common anomaly. ${ }^{29}$ Women with a unicornuate uterus have an increase incidence of infertility, endometriosis, and dysmenorrhea. ${ }^{30,31}$ They have a high risk of PL (40\%) and about half of them are lost within the first two trimesters. Fetal survival rates are poor. Akar reported a live birth rate of only $29 \%$ in women with unicornuate uterus. ${ }^{32}$ Obstetric complications such as breech presentation, fetal growth restriction, and cesarean delivery are also more common. ${ }^{33}$

An unicornuate uterus can present a variable degree of aplasia/ hypoplasia of one horn. So we can identify unicornuate uterus with rudimentary horn and with no rudimentary horn. There are two main subgroups of the unicornuate uterus:

- Complete unilateral agenesis or type II-d (also called true unicornuate uterus) is characterized by missing of one uterine horn (or the horn is just rudimentary) (Fig. 6D). 2D sonography shows a deviated uterus to one side, but generally the spindle-shaped aspect of the cavity is easily recognized by 3D sonography, MRI, or hysterosalpingography.

- Incomplete unilateral agenesis or type II (and subtypes Ila, Ilb, and IIC); also called pseudounicornuate uterus (Figs 6A to $C$ and Fig. 7). ${ }^{34-38}$ This form is much more frequent than the previous ones. In this case, the rudimentary horn of variable development is present. The horn can be attached or in some distance from the normal horn. It can be solid or with cavity paved with endometrium. Data from the literature indicate that approximately $65 \%$ of unicornuate uteri have an associated rudimentary horn. About $31 \%$ of them contained endometrial tissue and one-half of them communicate with the main endometrial cavity. A rudimentary horn without endometrial cavity was present in $34 \%$ of cases. ${ }^{39}$ Pregnancies in the rudimentary horn can be the seat of an ectopic pregnancy and when it happens in a noncommunicating horn, the risk of uterine rupture is high.

\section{Diagnosis and Management}

On physical examination, the uterus is markedly deviated on the left or right, reflecting the developmental failure of one of the Müllerian ducts. The unicornuate uterus can be diagnosed by HSG, ultrasonography, or MRI. HSG shows a deviated banana-shaped
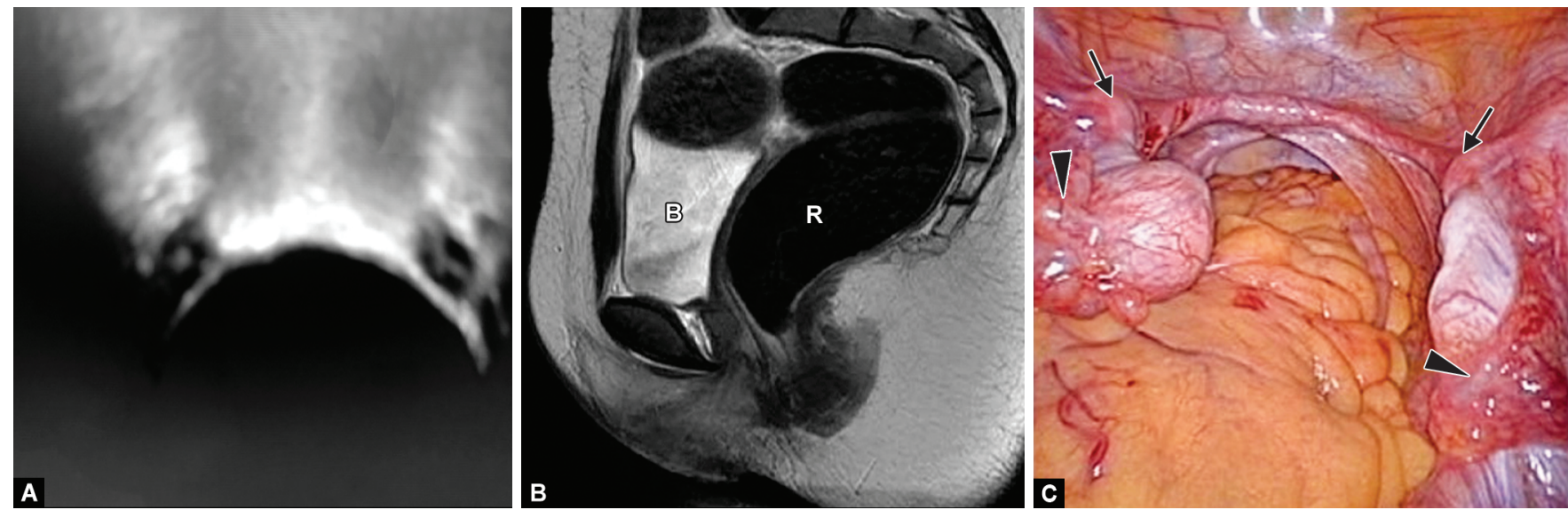

Figs 5A to C: Mayer-Rokitanski-Kuster-Hauser syndrome. (A) Ultrasound; (B) MRI (B, bladder and R, rectum); (C) Laparoscopy. The arrows are the round ligaments of the uterus and the arrowheads are the fallopian tubes and ovaries. Source: Kara T, Acu B, Beyhan M, et al. MRI in the diagnosis of Mayer-Rokitansky-Kuster-Hauser syndrome. Diagn Interv Radiol. 2013;19:227-232. ${ }^{21}$ Hall-Craggs MA, Williams CE, Pattison SH, et al. MayerRokitansky-Kuster-Hauser syndrome: diagnosis with MR imaging. Radiology. 2013;269:787-792. ${ }^{22}$
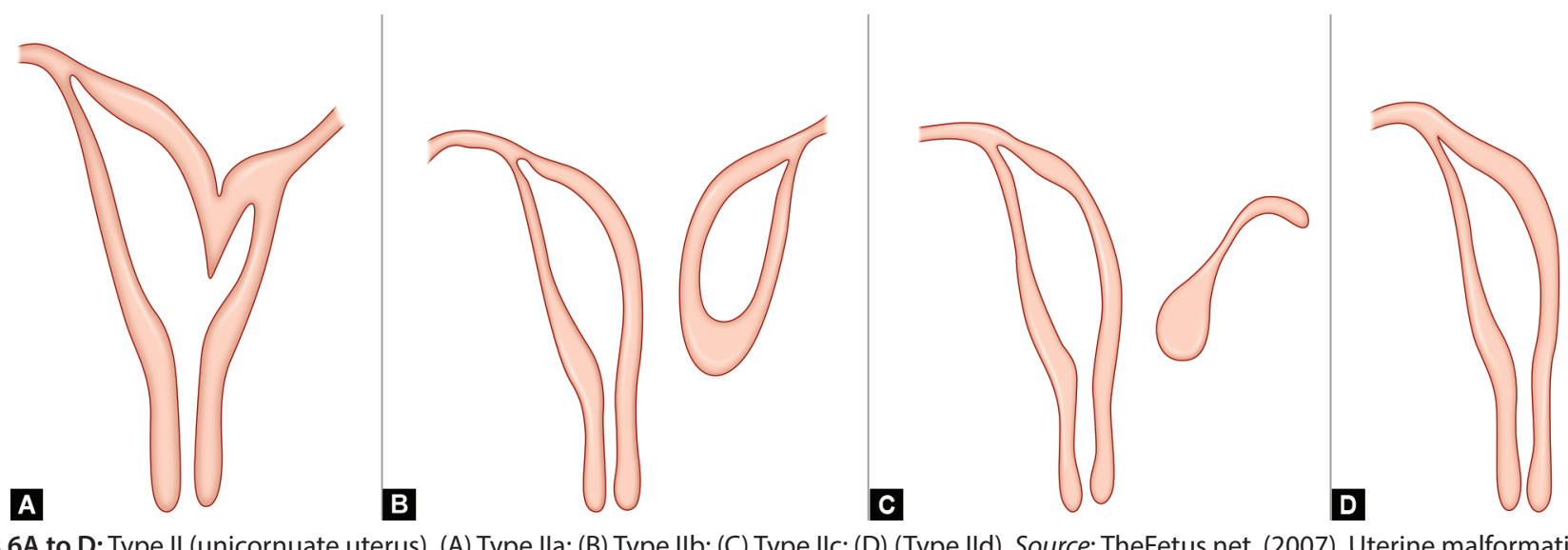

Figs 6A to D: Type II (unicornuate uterus). (A) Type Ila; (B) Type Ilb; (C) Type Ilc; (D) (Type Ild). Source: TheFetus.net. (2007). Uterine malformations. [online] Available from https://sonoworld.com/fetus/page.aspx?id=2150 [Accessed June, 2018]. ${ }^{34}$ 
cavity with a single fallopian tube (Fig. 8A). Rudimentary horn, in association with unicornuate uterus, can be better diagnosed by $2 \mathrm{D}$ sonography (presence of a horn tissue between the normal hemicavity and the contralateral ovary), but 3D sonography or MRI seem to be more precise (Fig. 8B). When a rudimentary uterine horn is present, TVS is able to visualize it as an echogenic image adjacent to the uterus. If there is no endometrial mucosa in the rudimentary uterine horn, this can appear as a pedunculated subserous myoma. In this case, the differential diagnosis can be difficult even for a skilled sonologist. In those cases, MRI can be
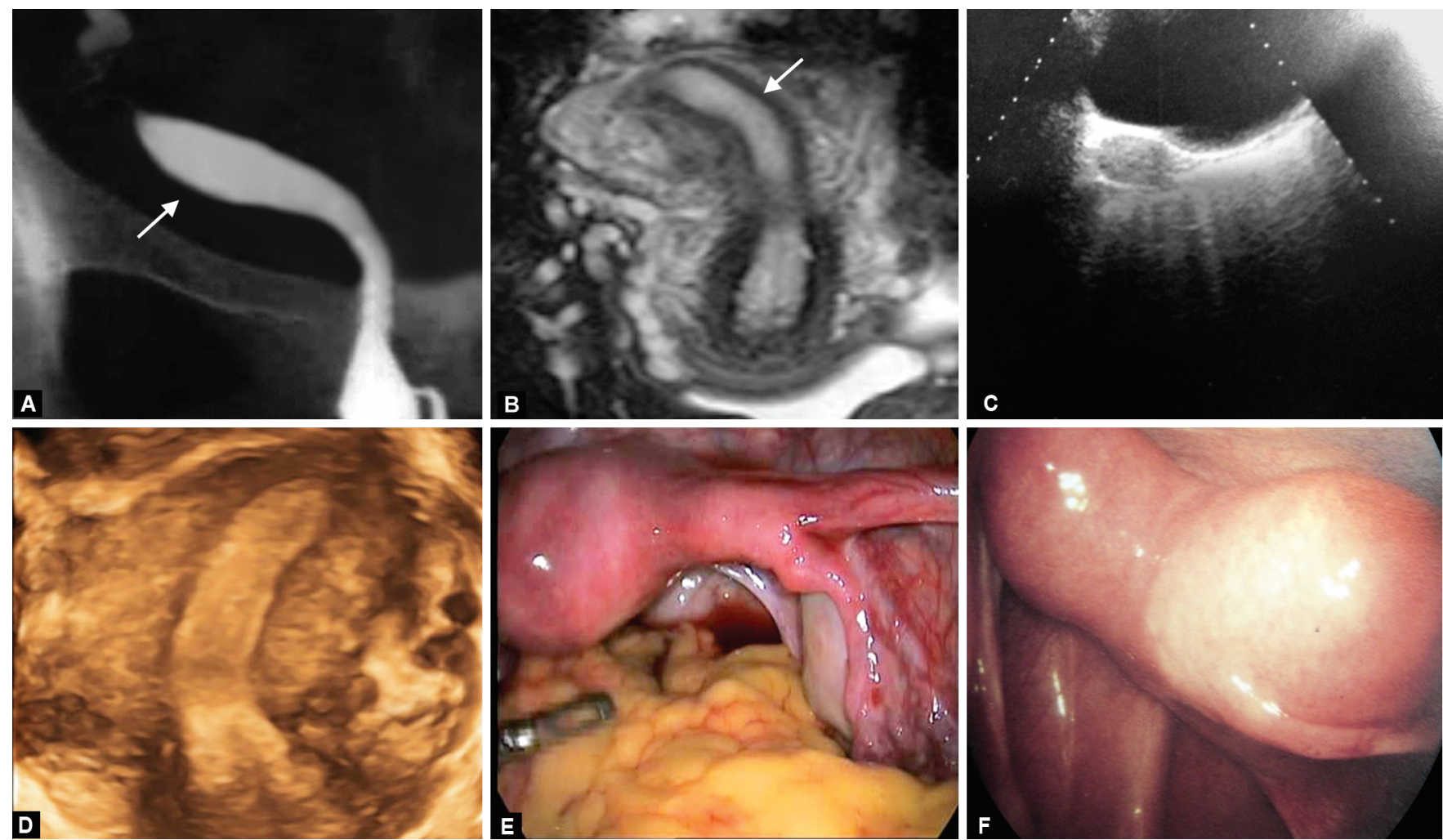

Figs 7A to F: Imaging of unicornuate uterus. (A) Type Ild [hysterosalpingography (HSG) images]; (B) Type IId (MRI images); (C) Type IId (2D US images); (D) Type Ild (3D US images); (E) Type Ilc; (F) Type Ilb [laparoscopy (LSC) images]. Sources: Medscape. (2016). Imaging in Mullerian Duct Abnormalities. [online] Available from https://emedicine.medscape.com/article/405335-overview [Accessed June, 2018]. ${ }^{35}$ Radiology Key. (2016). Congenital Uterine Anomalies. [online] Available from https://radiologykey.com/congenital-uterine-anomalies/[accessed June, 2018]. ${ }^{36}$ Patel MS. Rotator cuff tear. Radiopaedia. [online] Available from: https://www.radiopaedia.org/cases/rotator-cuff-tear-4. [Accessed June, 2017]. ${ }^{37}$ Rani A, Kumari M, Shipra. A case of noncommunicating uterine horn containing functional endometrium. Gynecol Obstet (Sunnyvale) 2015;5:320. DOI: $10.4172 / 2161-0932 .{ }^{38}$

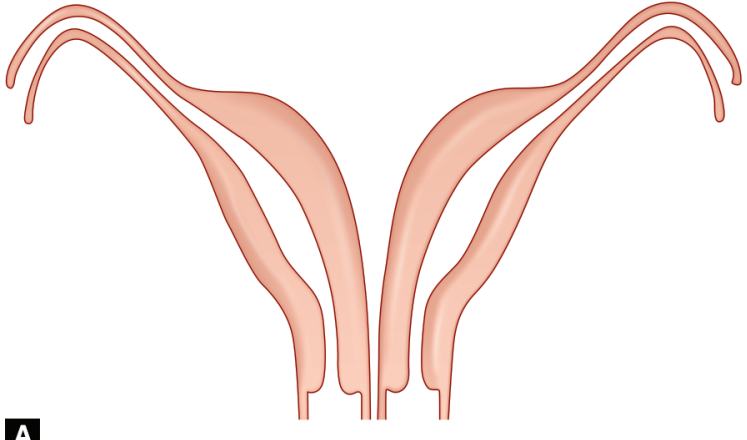

A

(A) Didelphic uterus (type III); (B) Didelphic uterus with obstructed hemivagina and renal unilateral agenesis. Sources: (A) Medscape. (2016). Imaging in Mullerian Duct Abnormalities. [online] Available from https://emedicine.medscape.com/article/405335-overview [Accessed June, 2018]..$^{35}$ (B) Sen KK, Balasubramaniam D, Kanagaraj V. Magnetic resonance imaging in obstructive Müllerian anomalies. J Hum Reprod Sci. 2013;6:162-164. ${ }^{40}$ 

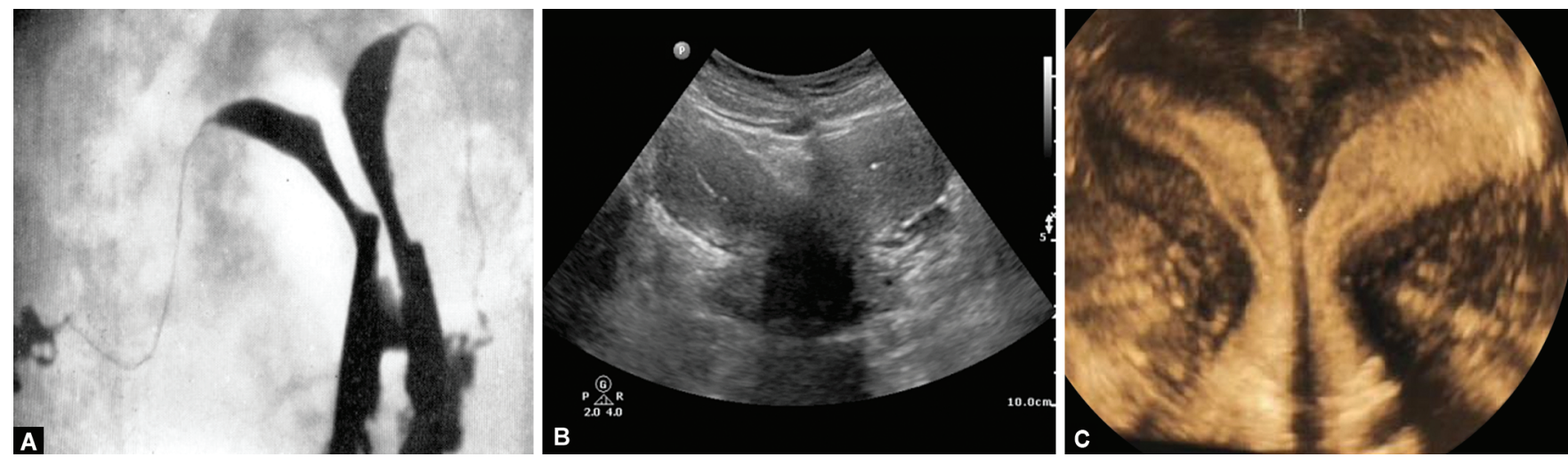

Figs 9A to C: Didelphic uterus: (A) Hysterosalpingography (HSG); (B) 2D ultrasound; (C) 3D ultrasound. Source: Wong L, White N, Ramkrishna J, et al. Three-dimensional imaging of the uterus: The value of the coronal plane. World J Radiol. 2015;7:484-493. ${ }^{43}$
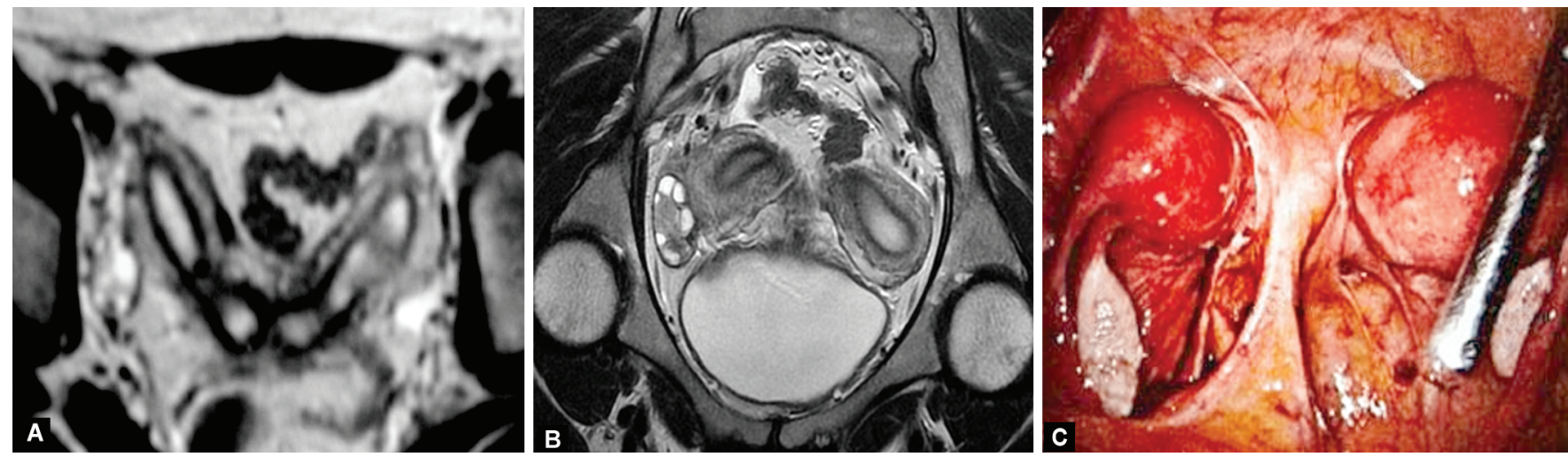

Figs 10A to C: Images of didelphic uterus. (A and B) Magnetic resonance imaging (MRI); (C) Laparoscopy (LSC). Source: Sakinala K. Anencephaly. Radiopaedia. [online] https://radiopaedia.org/cases/anencephaly-2?iframe=true [Accessed June, 2018]. ${ }^{44}$ Pissat S, Tas B, van Herendael B. Laparoscopic Strassman's metroplasty for bicornuate uterus. Gynecol Surg Endosc Imaging Allied Tech. 2009;6:463.45

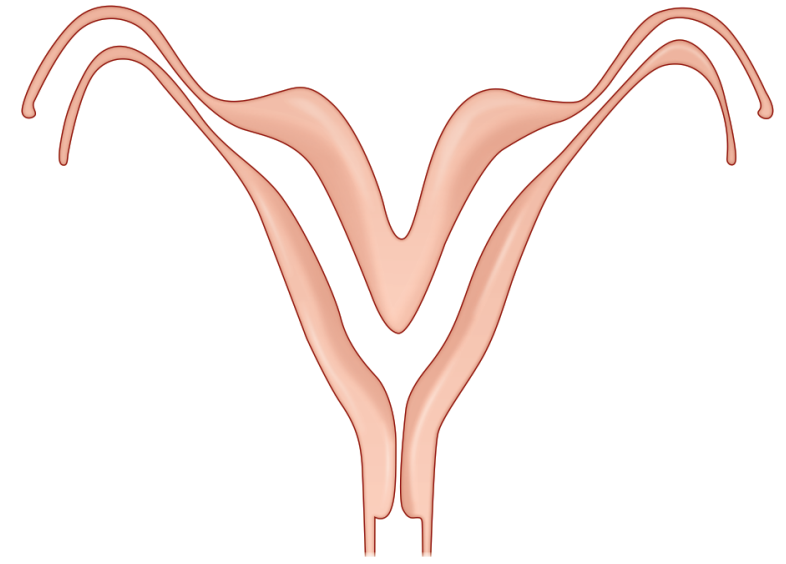

Fig. 11: Bicornuate uterus. Source: Medscape. (2016). Imaging in Mullerian Duct Abnormalities. [online] Available from https://emedicine. medscape.com/article/405335-overview [Accessed June, 2018]. ${ }^{35}$

more helpful for diagnosis, but in some cases only LSC allows to recognize this condition. ${ }^{35,40}$

\section{Perinatal Outcomes}

Unicornuate uterus, with its compromised uterine mass and sometimes associated uterine horns, brings with it considerable reproductive hurdles. Women with a unicornuate uterus have an increase incidence of infertility, endometriosis, and dysmenorrhea as well as IUGR, miscarriage, malpresentation, PL, and cervical incompetence. The risk of $\mathrm{PL}$ is about $40 \%$ and about half of them are lost within the first two trimesters. Akar reported a live birth rate of only $29 \%$ in women with unicornuate uterus. ${ }^{32}$ A review of 20 studies (1953-2006), 290 patients with unicornuate uterus, 486 pregnancies, report first trimester abortions- $24.3 \%$ and PD-20.1\%. ${ }^{41}$ Obstetric complications such as breech presentation, IUGR, and CD are also more common. Unfortunately, there is no treatment available for successive pregnancies in women with unicornuate uterus. But, in patients with a rudimentary horn with endometrium cavity inside, because of the high risk for maternal morbidity secondary to rupture of rudimentary horn in case of pregnancy and intraperitoneal hemorrhage, excision of this rudimentary horn is indicated whenever it is identified. ${ }^{41,42}$ In patients with rudimentary horn with no endometrium inside (solid rudimentary horn), removal is not indicated as no adverse effect on reproductive outcome has been reported.

\section{Failure of Fusion of Müllerian Ducts (Uterus Didelphys)}

These anomalies are related to defective fusion of the Müllerian ducts. The complete failed fusion form represents didelphic uterus (Figs 8 to 10). The incomplete lateral fusion form represents bicornuate uterus (Fig. 11). ${ }^{35,40,43-45}$

Didelphic uterus or type III is characterized by the presence of two noncommunicating endometrial cavities, each with a uterine 
cervix and a fallopian tube (Fig. 8A). ${ }^{35} \mathrm{~A}$ longitudinal vaginal septum between two cervices is present in most cases. Occasionally, one hemivagina is obstructed by an oblique vaginal septum. In this condition, asymmetry of the vagina may result in complete closure of one-half, with subsequent cryptomenorrhea and hematometra, but with apparently normal menstrual function. ${ }^{46,47}$ This anomaly is often associated with ipsilateral renal agenesis (Fig. 8B). ${ }^{40}$

\section{Diagnosis and Management}

Uterus didelphys should be suspected if a longitudinal vaginal septum or if two separate cervices are found. This anomaly may be diagnosed with HSG, where we can see two completely separate canals, opening into fusiform cavities, each with a solitary fallopian tube (Fig. 9A). With this technique we can also identify the possibility of communication between cavities. ${ }^{4,48}$

Sonography can help us to identify this anomaly (Fig. 9B), but it is not always easy to differentiate on 2D ultrasound a bicornuate from a didelphic uterus. 3D ultrasound (Fig. 8C) and MRI (Fig. 10A) can provide us better images for differential diagnosis between didelphic, bicornuate, and septate uterus. Laparoscopy is also a gold standard diagnostic tool especially when other techniques fail diagnosis (Fig. 10B).

\section{Perinatal Outcomes}

The perinatal prognosis of didelphic uterus is better when compared with unicornuate uterus. The mechanism is unclear but probably didelphic uterus has an improved blood supply through collateral connections between the two horns. Pregnancies are more commonly located in the right uterus (76\%). ${ }^{49}$ An infertility rate of $13 \%$ has been reported from a study of 49 women with a mean follow-up of 9 years. ${ }^{49}$ A review of 114 patients with untreated uterine didelphys who had a total of 152 pregnancies exhibited a mean miscarriage rate of $32.9 \%$ and preterm delivery rate of $28.9 \%$, with a live-birth rate quoted as $56.6 \% .{ }^{50}$ Some authors recommend Strassman reunification of two horns, but it should not routinely be undertaken, except in circumstances of repeated pregnancy loss or preterm delivery in the absence of other etiologies. ${ }^{51}$ Resection of a vaginal septum associated with uterus didelphys should be undertaken if associated with obstruction, dyspareunia or infertility.

\section{Bicornuate Uterus}

Bicornuate unicervical uterus or type IVa or IVb. In this case, the uterus consists of one cervix and two divergent horns. There are two separate but communicating endometrial cavities and myometrium is surrounding each cavity (Fig. 11). The outside top or fundus of the uterus is indented or "heart-shaped". ${ }^{35}$ The difference between a septate and a bicornuate uterus is either made visually, at 3D ultrasound (Fig. 10C), MRI, or on LSC, where you can distinguish between a heart-shaped uterus and a normal shaped uterus. Several studies suggest that women with a bicornuate uterus can expect reasonable success (60\%) in delivering a living child. ${ }^{52}$ The embryo attaches and continues to develop because it has adequate blood flow, but frequently results in premature labor generally around 22-32 weeks because the pregnancy is only growing in "half a uterus".

\section{Diagnosis and Treatment}

Hysterosalpingography is the initial diagnostic step in evaluating a possible bicornuate uterus (Fig. 12A). Frequently, the uterine horns show a marked divergence (wide angle $105^{\circ}$ separating cavities), but various morphologic forms are possible. So, more often this technique cannot differentiate a bicornuate from a septate uterus and additional testing (ultrasound, MRI, or LSC) are necessary to make a correct diagnosis. The main sonographic feature of the uterine duplications is an invagination of the uterine fundus, well seen on coronal views (or by 3D sonography and MRI). The spacing between the horns with the urinary bladder in the gap between the horns can be recognized as a "V sign" of the bladder. The differential diagnosis can be difficult with a septate uterus when the spacing between the horns is small. The fundal invagination bigger than $1 \mathrm{~cm}$ of depth and a distinct vascularization on color Doppler images testify the bicornuate uterus. 2D sonography is helpful to differentiate a bicornuate from a septate uterus but it is not easy to differentiate only with 2D ultrasound a bicornuate from a didelphic uterus (Figs 12B and C). 3D ultrasound and MRI are more helpful due to their capability in demonstrating both the endometrial and myometrial contours (Figs 12D and E). Laparoscopy is sometimes required for a definitive diagnosis, when the differential diagnosis is difficult (Fig. 12F). ${ }^{35,36,53,54}$

\section{Perinatal Outcomes}

Perinatal outcomes are generally reported to be better than in unicornuate uterus, perhaps because a partially fused central uterine cavity. A $36 \%$ abortion rate and $23 \%$ preterm delivery rate have been quoted, but we know that many asymptomatic patients still may escape detection. ${ }^{50}$ In patients with repeated pregnancy loss in whom other causes have been excluded, laparoscopic or abdominal metroplasty serves as a possible treatment modality to improve obstetric outcomes. ${ }^{55}$ Strassman technique was designed to unify equal-sized endometrial cavities with good pregnancy outcomes. ${ }^{56}$ The actual benefit of hysteroscopic metroplasty for a bicornuate uterus, however, has not been tested in a controlled clinical series. We do not recommend metroplasty at the time of diagnosis for patients with primary infertility, given that fertility rates are not significantly reduced from the norm and successful pregnancies without intervention are common. Patients should be counseled regarding the need for subsequent cesarean section, given the significant risk of uterine rupture during labor after such procedures.

\section{Septate Uterus}

Uterine septations belong among most frequent uterine malformations. Septations are secondary to the total or partial defect of resorption of the medial segments of the Müllerian ducts, creating a permanent septum within the uterine cavity. In these malformations, the external contours of the uterus are normal. On a coronal section, the fundal serosa is rectilinear or with mild invagination $(<1 \mathrm{~cm})$. The single uterine cavity is divided by a bridge of fibrous myometrium. The septum is in generally hypovascularized in comparison to the adjacent myometrium. The septum can project minimally from the uterine fundus or can extend completely to the cervical os (Fig. 13). ${ }^{34}$ Moreover, septum can develop segmentally, resulting in partial communication of the partitioned uterus. Septate uterus is associated with a marked increase in spontaneous abortion. ${ }^{57}$ Woelfer reported a first trimester (generally between 8 weeks and 12 weeks) spontaneous abortion rate for septate uterus of $42 \% .{ }^{58}$ The histologic structure of septa ranges from fibrous to fibromuscular. This connective tissue has poor blood supply and when an embryo attaches to it, the uterus cannot supply adequate blood flow and nutrients. The diminished blood supply, combined with distortion of uterine cavity and cervical or endometrial abnormalities, is probably the cause 

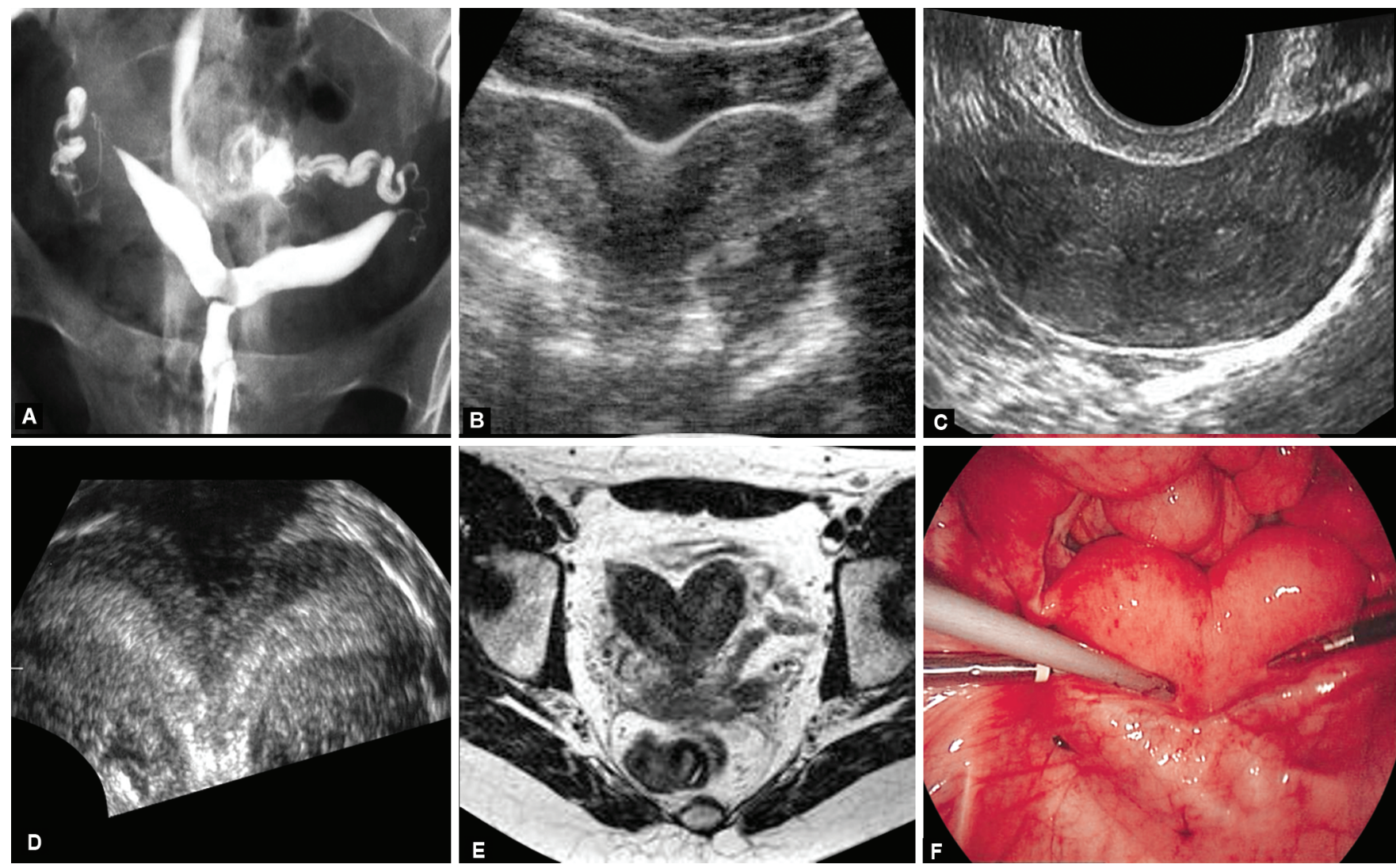

Figs 12A to F: Images of bicornuate uterus. (A) Hysterosalpingography (HSG); (B) 2D US; (C) 3D US; (D) MRI; (E and F) Laparoscopy. Sources: Radiology Key. (2016). Congenital Uterine Anomalies. [online] Available from https://radiologykey.com/congenital-uterine-anomalies/ [accessed June, 2018]. ${ }^{36}$ Medscape. (2016). Imaging in Mullerian Duct Abnormalities. [online] Available from https://emedicine.medscape.com/article/405335-overview [Accessed June, 2018]. ${ }^{35}$ Morgan MA. ${ }^{53}$ Matsaseng T, Kruger TF. Laparoscopic Strassman's metroplasty for bicornuate uterus-is it relevant? S Afr J Obstet Gynaecol. 2012;18:85-87. ${ }^{4}$
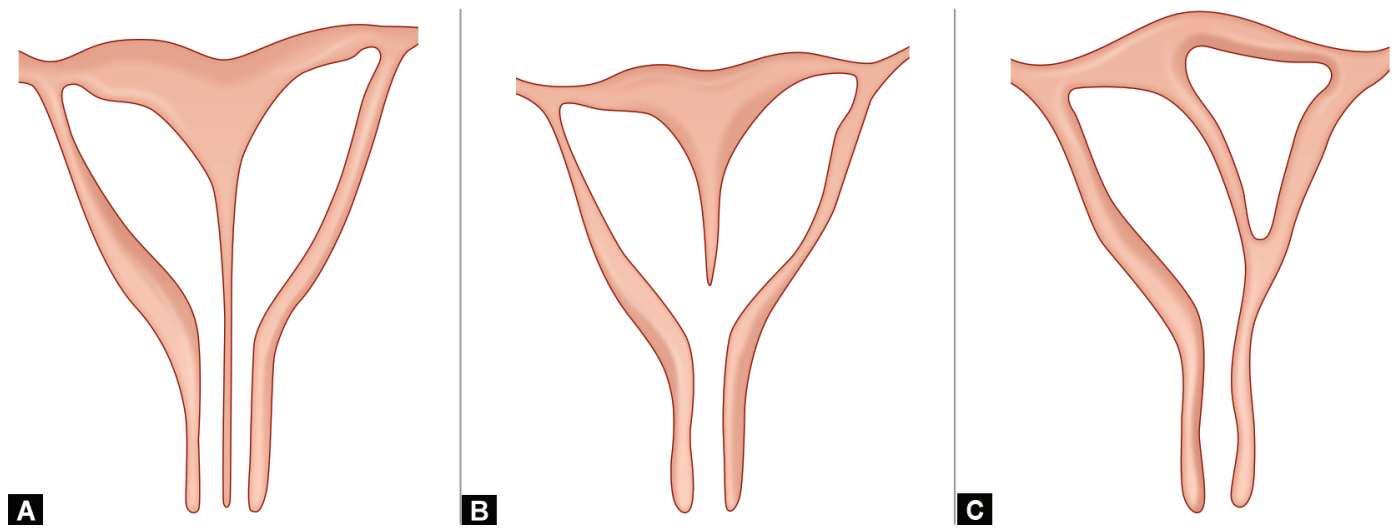

Figs 13A to C: Septate uterus. (A) Type Va; (B) Type Vb; (C) Asymmetric septate uterus. Source:TheFetus.net. (2007). Uterine malformations. [online] Available from https://sonoworld.com/fetus/page.aspx?id=2150 [Accessed June, 2018]. ${ }^{34}$

of the first trimester pregnancy loss. The true incidence of these anomalies is not known because they are usually only detected in women with obstetric complications. These anomalies are usually not accompanied by renal anomalies.

Complete septate uterus or type Va: The septum extends from the uterine fundus to the external os of the cervix. This can imitate duplicity of the cervix. Vagina can be sometime also septated.

Partial, corporeal, fundal septate uterus or type Vb: In this case, the septum is located above the cervix.
Asymmetric septate uterus: This rare form was described in the Musset's classification but is absent in the AFS classification. The uterine body is divided into two asymmetric cavities by a septum going from the uterine fundus to the uterine isthmus. One of the two cavities communicates with the cervix and the other is blind with consequent risk of hematometra, endometriosis, or ectopic pregnancy (Fig. 13C).

Uterine communications: These malformations are very rare. The uterus has an isthmic communication between the cavities of the 
bicornuate or septate uterus (Fig. 14). The diagnosis can be done by HSG, 3D sonography, or MRI. ${ }^{34}$

\section{Diagnosis}

Diagnosis of the septate uterus includes HSG, sonography, and MRI. The images of a septate uterus in HSG are very similar with those of bicornuate uterus (Figs 15A to D), but in most part of cases with septate uterus the acute angle of separation between the endometrial cavities is smaller, compared with a bicornuate uterus (less than $75^{\circ}$ ). As the morphologic variations are very large, sometimes the differential diagnosis only by HSG is not easy.

Sonography can help us to see two endometrial cavities separated by hypoechoic myometrium. The fundal contour is

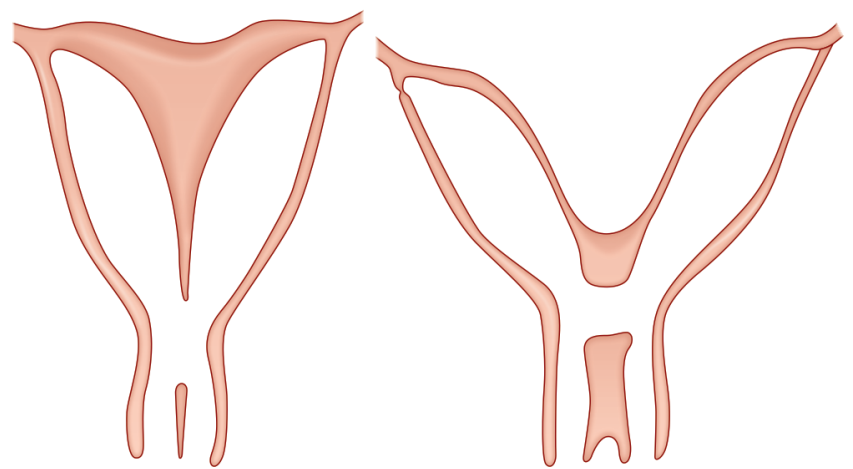

Fig. 14: Examples of communicating uteri. Source: TheFetus.net. (2007). Uterine malformations. [online] Available from https://sonoworld.com/ fetus/page.aspx?id=2150 [Accessed June, 2018]. ${ }^{34}$ slightly concave or flat. The thickness and depth of the septum can be evaluated by integrating the transversal and longitudinal scans. 3D ultrasound permits precise depiction of size and extent of septum as well as MRI (Figs 15E and F). ${ }^{35,54}$

\section{Treatment and Perinatal Outcomes}

A septate uterus can be corrected with surgery, resulting in a unified uterine cavity, allowing the pregnancy to go close to term. Prior to use of HSC procedures, abdominal metroplasty for septate uterus was the technique of choice to cut the septum and improve the fetal survival. The disadvantages of abdominal metroplasty include the cesarean delivery, to prevent uterine rupture, high rate of pelvic adhesion formation and subsequent infertility. Currently, hysteroscopic septum resection (Fig. 16) is an easy, effective, and safe alternative to treat this pathology. ${ }^{59}$

Several studies cite profound rates of adverse obstetrical outcomes associated with uterine septa, with fetal survival rates of $6-28 \%$ and a rate of spontaneous miscarriage as high as more than or equal to $60 \% .{ }^{52,60}$ Patients with septate uterus and no other cause of infertility had significantly higher probability of conceiving subsequent to metroplasty ( $38.6 \%$ vs $20.4 \%$ ) as well as exhibiting higher rates of live birth (34.1\% vs $18.9 \%) .{ }^{61}$ Gordts, on 2012, reported that hysteroscopic metroplasty dramatically improves pregnancy outcome, reducing the miscarriage rate and increasing term delivery. ${ }^{62}$ In another Cochrane systematic review studying metroplasty vs expectant management for women with recurrent miscarriage and a septate uterus, authors' conclusion was: hysteroscopic metroplasty treatment in women with RPL and a septate uterus has been assessed in non-controlled studies, which
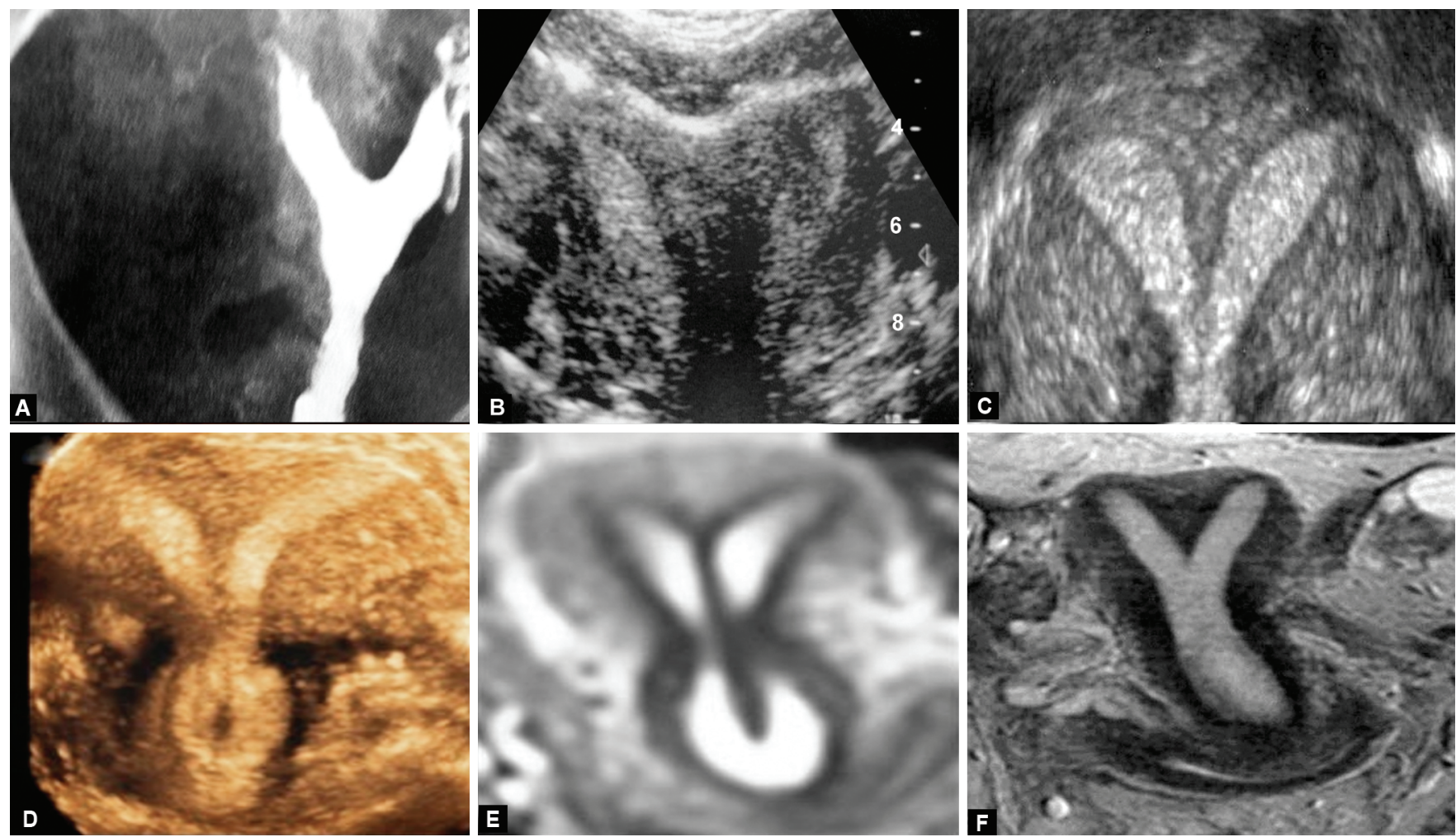

Figs 15A to F: Septate uterus. (A) HSG; (B) 2D US; (C) 3D US—partial septum; (D) 3D US—complete septum; (E) MRI-complete septum; (F) MRI_partial septum. Source: Radiology Key. (2016). Congenital Uterine Anomalies. [online] Available from https://radiologykey.com/congenitaluterine-anomalies/ [accessed June, 2018]. ${ }^{36}$ Medscape. (2016). Imaging in Mullerian Duct Abnormalities. [online] Available from https://emedicine. medscape.com/article/405335-overview [Accessed June, 2018]..$^{35}$ (Source for Fig. 15B: http://www.elceclinics.com/images/hysteroscopic_resection_ of_septum1.jpg) 

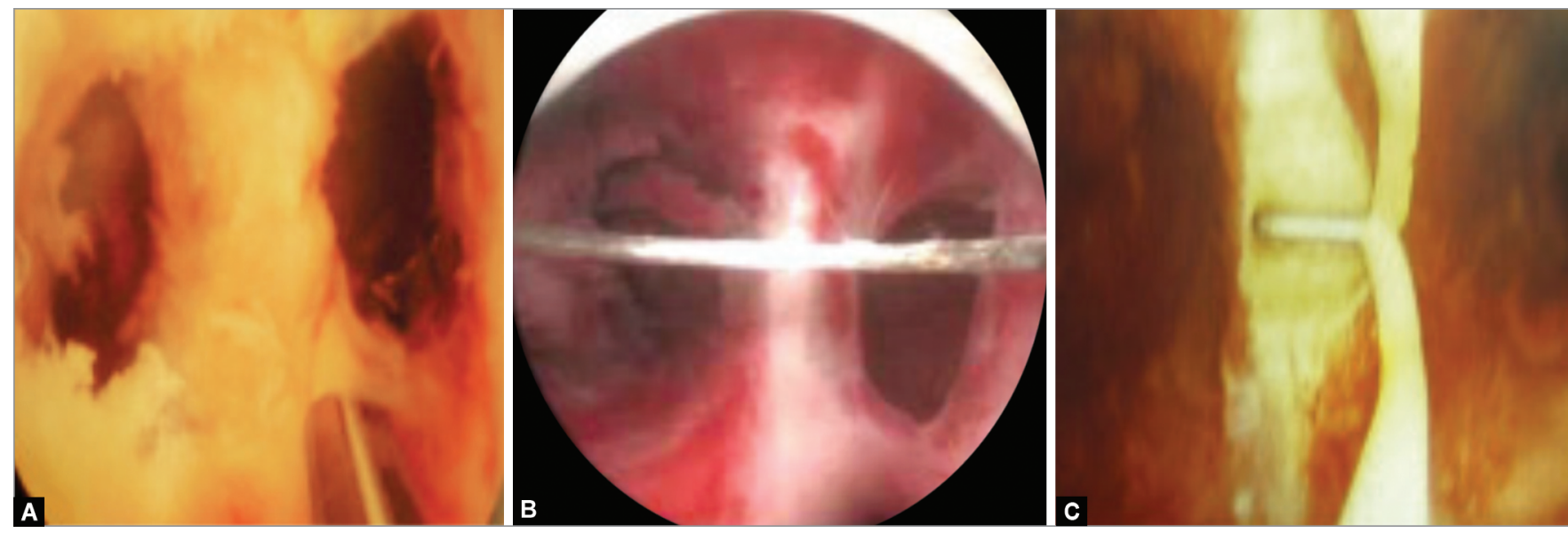

Figs $16 \mathrm{~A}$ to $\mathrm{C}$ : Hysteroscopic treatment of a septate uterus
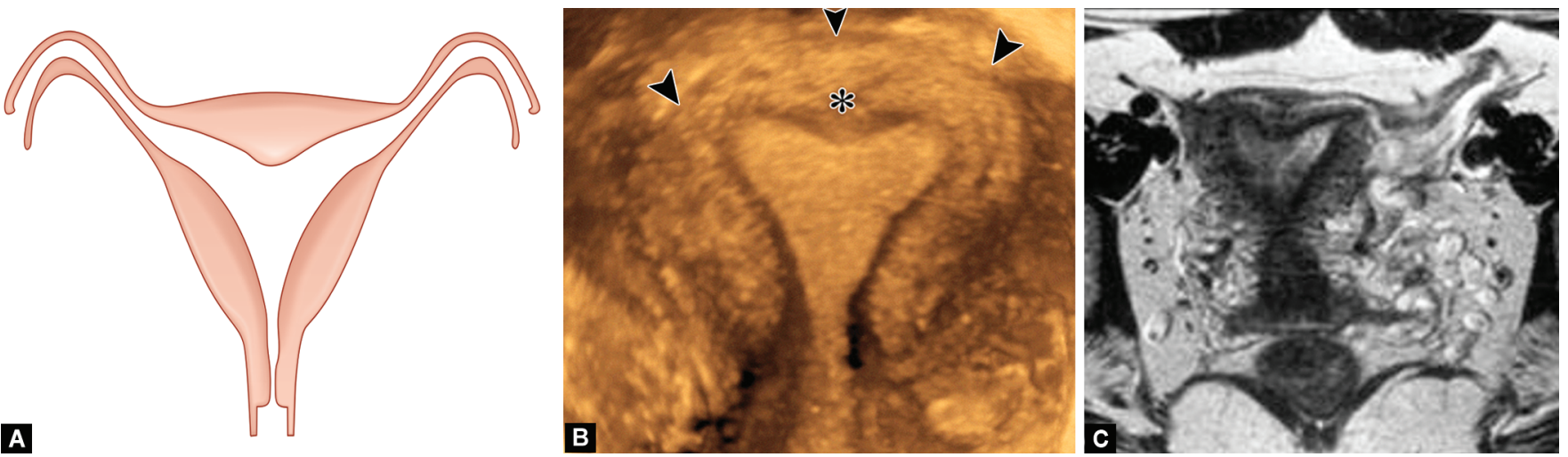

Figs 17A to C: Arcuate uterus. (A) Schematic; (B) US; (C) MRI. Sources: Medscape. (2016). Imaging in Mullerian Duct Abnormalities. [online] Available from https://emedicine.medscape.com/article/405335-overview [Accessed June, 2018]..$^{35}$ Behr SC, Courtier JL, Qayyum A. Imaging of müllerian duct anomalies. Radiographics. 2012;32:E233-E250. ${ }^{64}$

suggested a positive effect on pregnancy outcomes. However, these studies are biased due to the fact that the participants with recurrent miscarriage treated by hysteroscopic metroplasty served as their own controls. Taking this into account, there is insufficient evidence to support this treatment in these patients. ${ }^{63}$ It remains more controversial whether uterine septa, which are incidentally detected prior to child-bearing, should be prophylactically removed prior to attempting conception. For those patients undergoing workup for infertility or beginning the process of ART, we recommend HSC resection of septum, in order to optimize the uterine cavity prior to expensive interventions and in terms of minimizing adverse obstetrical outcomes once pregnancy is achieved.

\section{Arcuate Uterus}

An arcuate uterus is a mild variant between a normally developed and septated uterus. By definition, an arcuate uterus has an intrauterine indentation in the fundus of the uterus of less than $1 \mathrm{~cm}$ (Fig. 17). The ratio of height to fundal indentation to the intercornual distance is less than $10 \%$. $^{35,64}$

The uterus is formed during embryogenesis by the fusion of the two Müllerian ducts. During this fusion a resorption process eliminates the partition between the two ducts to create a single cavity. This process begins caudally and advances cranially, thus an arcuate uterus represents an, in the final stage, incomplete absorption process. Helpful techniques to investigate the uterine fundus structure are transvaginal ultrasonography SHG, hysterosalpingography, MRI, and HSC. More recently 3D ultrasonography has been advocated as an excellent noninvasive method to delineate the condition. The major differential diagnosis is the uterine septum. The lack of agreement to separate these two entities makes it difficult to assess the results in the literature.

\section{Perinatal Outcomes}

Most of the women with an arcuate uterus do not have any reproductive consequences. Many clinicians consider it as a "normal" variation and do not recommend surgical repair. However, several studies have implicated arcuate uterus as being associated with poor obstetric outcomes, although such claims remain controversial, given the retrospective nature of such reports and the variability in reported numbers between studies. ${ }^{65}$ Wöelfer found excessive second trimester losses and PL in this group. ${ }^{58}$ Cited rates of live birth vary widely, from as low as $45 \%$ to as high as $82.7 \% .{ }^{33}$ We are inclined to believe, based on our own experience and our understanding of the arcuate anatomy, the more optimistic reproductive data. Women with such anomalies do not benefit from surgical intervention in the absence of other anomalies and such patients should be reassured of their high likelihood for successful reproduction. So, surgical resection is recommended only after 

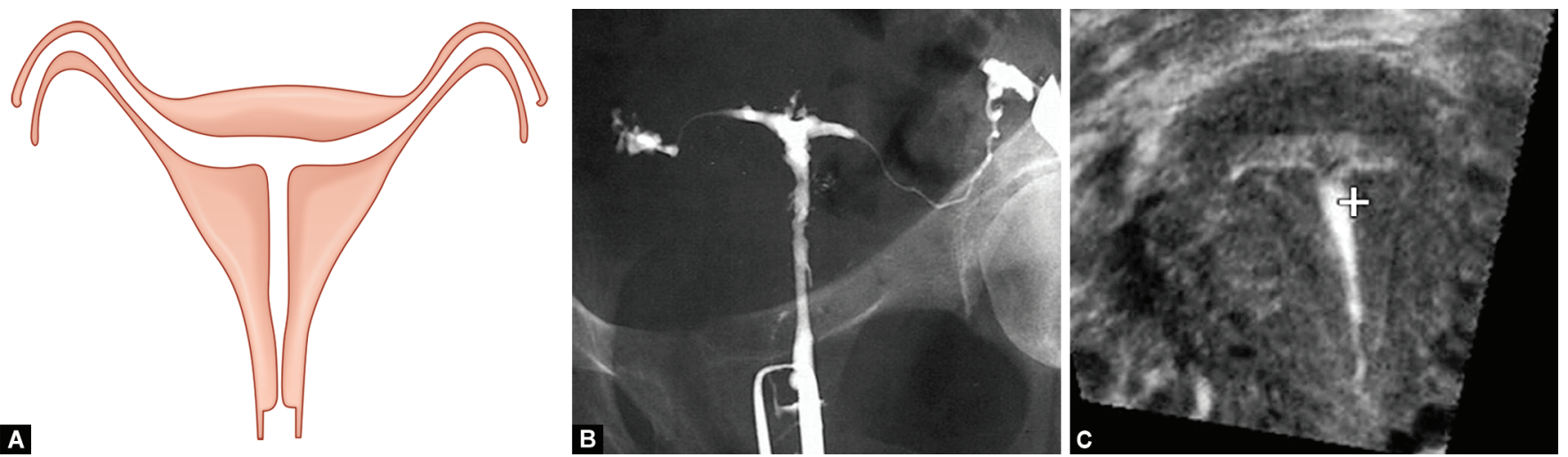

Figs 18A to C:T-shaped uterus. (A) Schematic; (B) HSG; (C) US. Source: Medscape. (2016). Imaging in Mullerian Duct Abnormalities. [online] Available from https://emedicine.medscape.com/article/405335-overview [Accessed June, 2018]. ${ }^{35}$ Steinkeler JA, Woodfield CA, Lazarus E, et al. Female infertility: a systematic approach to radiologic imaging and diagnosis. Radiographics. 2009;29:1353-1370. ${ }^{67}$

excessive pregnancy losses and when other etiologies for recurrent spontaneous abortions have been excluded.

\section{Acquired Uterine Defects}

Another group of uterine anomalies, except congenital anomalies, are acquired defects such as diethylstilbestrol (DES) exposure, synechia or intrauterine adhesion formation (Asherman syndrome), and uterine myomas. These defects are recognized as contributors to infertility, pregnancy loss, preterm delivery, or menstrual disorders.

\section{Diethylstilbestrol-induced Reproductive Tract Anomalies (or T-shaped Uterus)}

It is due to maternal exposure to DES, a drug used in the 50-60 $s$ to help prevent miscarriages and preterm delivery. DES has been known to be associated with benign vaginal adenosis, such structural cervical changes as collars, hoods, septae, T-shaped uteri, constriction bands, wide lower uterine segments, and irregular endometrial cavity borders. Some consequences of maternal DES exposure were reduced fertility, a T-shaped (or hypoplastic or underdeveloped) uterus in female offspring, and cervical hypoplasia or atresia. A T-shaped uterus is associated with the highest rate of first trimester spontaneous abortions and the lowest rate of term deliveries because of the decreased uterine size. ${ }^{35,66,67}$ It cannot be repaired by surgery and if a woman continues to have reproductive failure, she may consider closed her gestational carrier (Fig. 18).

\section{Perinatal Outcomes}

The poor perinatal outcomes in this group are caused not only by the uterine anomaly but also by the antiestrogenic effect at the endometrium. The resulting insufficient endometrial environment leads to ectopic pregnancy, miscarriage and PL. In a meta-analysis study of DES exposed subjects the authors found a ninefold increase in ectopic pregnancy, a twofold increase in miscarriage rate and a twofold increase in preterm delivery compared with a matched control population. ${ }^{68}$ Pregnancy rates were similar between DESexposed women and controls ( $72 \%$ vs $79 \%$ respectively). Such outcomes are caused not only by the uterine anomaly but also by antiestrogenic effect at the endometrium. The resulting insufficient endometrial environment for the early conceptus leads to ectopic pregnancy, PL, and miscarriage but not necessarily infertility.

\section{Asherman's Syndrome}

Asherman's syndrome is a condition characterized by adhesions and/or fibrosis of the endometrium particularly but can also affect the myometrium. This is an acquired uterine disorder characterized by intrauterine adhesions (Fig. 19). ${ }^{36,69,70}$ It is often caused by curettage of the uterine cavity. About $88 \%$ of them are found after a postabortum or postpartum uterine curettage (Schenker 1982). ${ }^{71}$ A number of other terms have been used to describe the condition and related conditions including: intrauterine adhesions, uterine/cervical atresia, endometrial sclerosis, and intrauterine synechiae. Various classification systems were developed to describe Asherman's syndrome, some taking into account the amount of functioning residual endometrium, menstrual pattern, obstetric history, or the location and severity of adhesions inside the uterus. This is useful as mild cases with adhesions restricted to the cervix may present with amenorrhea and infertility, showing that symptoms alone do not necessarily reflect severity. Other patients may have no adhesions but amenorrhea and infertility due to a sclerotic atrophic endometrium. The latter form has the worst prognosis.

When the syndrome is suspected, HSG or HSC is indicated. Intrauterine adhesions appear on HSG as irregular, angulated filling defects within the uterine cavity (Figs 19A and B). The spectrum of scarring can range from isolated defects to complete obliteration of the uterine cavity. A differential diagnosis has to be done with uterine polyps, myomas, and air bubbles. When the diagnosis is confirmed, dilation and curettage (D\&C) or hysteroscopic surgical treatment of adhesions is recommended. Anyhow, many authors reported excellent reproductive outcome after hysteroscopic treatment compared with $D \& C$, even when severe intrauterine adhesions are identified. ${ }^{72-74}$

The extent of adhesion formation is critical. Mild-to-moderate adhesions can usually be treated with success. Pregnancy and live birth rate has been reported to be related to the initial severity of the adhesions with $93 \%, 78 \%$, and $57 \%$ pregnancies achieved after treatment of mild, moderate, and severe adhesions, respectively and resulting in $81 \%, 66 \%$, and $32 \%$ live birth rates, respectively. ${ }^{74}$ The overall pregnancy rate after adhesiolysis was $60 \%$ and the live birth rate was $38.9 \%$ according to one study. ${ }^{75}$ Extensive obliteration of the uterine cavity or fallopian tube ostia and deep endometrial 

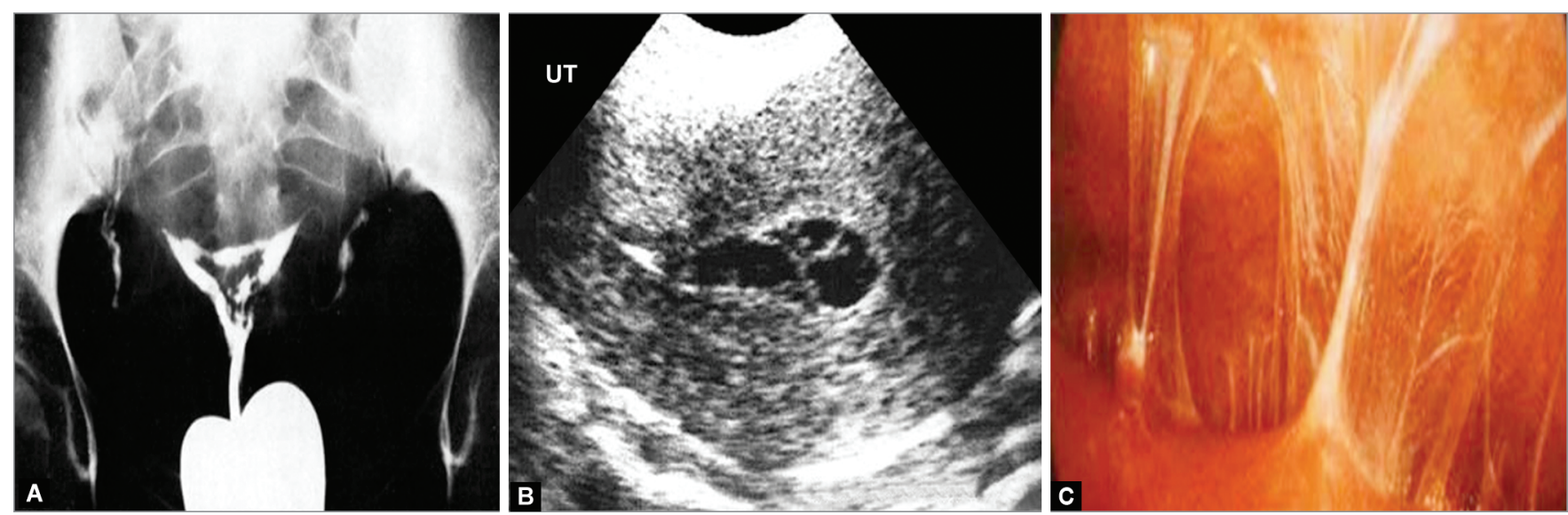

Figs 19A to C: Asherman's syndrome. (A) HSG; (B) 2D US; (C) HSC-intrauterine adhesive bridges. Source: IVF-Infertility.com. (2016). Asherman's syndrome. [online] Available from http://www.ivf-infertility.com/infertility/ashermans.php [Accessed June, 2018] ${ }^{69}$ Silver S. $^{70}$
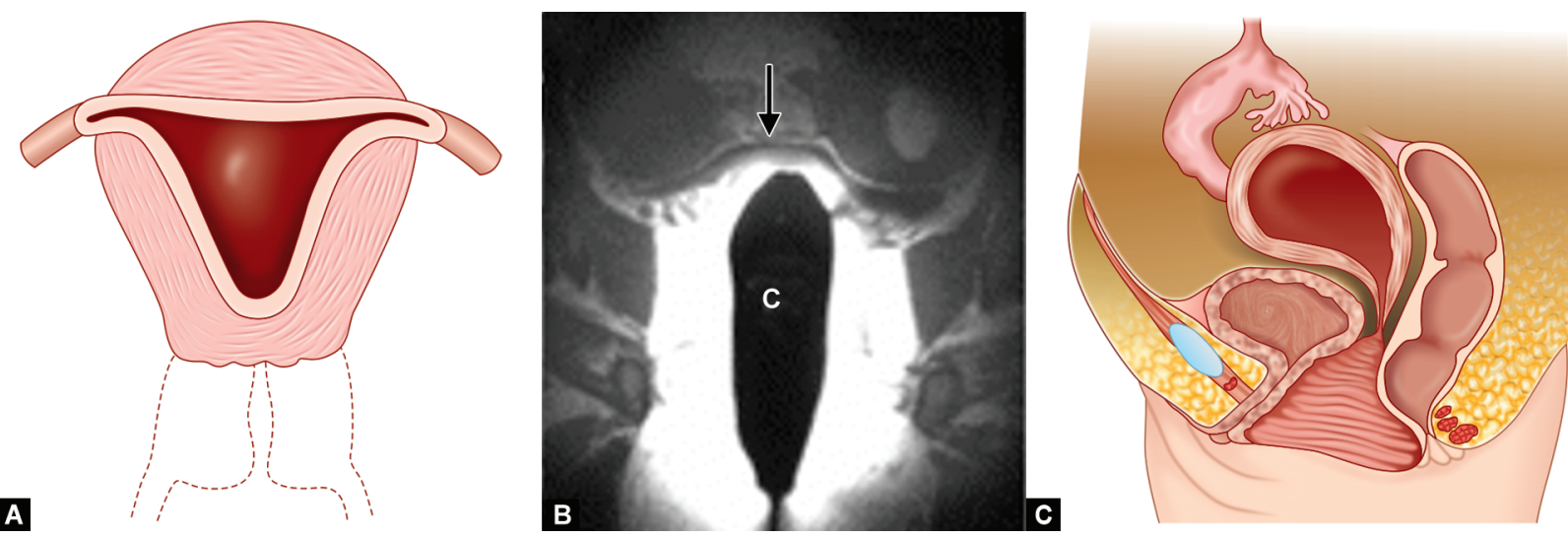

Figs 20A to C: Cervical agenesis. Source: Steinkeler JA, Woodfield CA, Lazarus E, et al. Female infertility: a systematic approach to radiologic imaging and diagnosis. Radiographics 2009;29:1353-1370.67

or myometrial trauma may require several surgical interventions and/or hormone therapy or even be uncorrectable. If the uterine cavity is adhesion free but the ostia remain obliterated, IVF remains an option. If the uterus has been irreparably damaged, surrogacy or adoption may be the only options.

\section{Some Other Female Genital Tract Defects}

\section{Cervical Agenesis}

Cervical agenesis is a congenital disorder of the female genital system that manifests itself in the absence of a cervix, the connecting structure between the uterus and vagina (Fig. 20). ${ }^{67}$ Milder forms of the condition, in which the cervix is present but deformed and nonfunctional, are known as cervical atresia or cervical dysgenesis. Patients with cervical agenesis typically present in adolescence, around the time of menarche, with amenorrhea and cyclic pelvic pain caused by the obstruction of menstrual flow from the uterus. Cervical agenesis arises during fetal development, during which time the paramesonephric duct fails to canalize in formation of the cervix.

Women with congenital absence of the cervix typically also lack the upper vagina. The uterus, however, usually develops normally, so these patients present primary amenorrhea and cyclic abdominal or pelvic pain. Patients may have a distended uterus and a high risk for developing endometriosis, secondary to retrograde menstrual flow. A single midline uterine fundus is the most frequent, although bilateral hemiuteri are also described. ${ }^{76}$ If untreated, the accumulation of menstrual fluid in the uterus caused by cervical agenesis can lead to hematocolpos, hematosalpinx, endometriosis, endometrioma, and pelvic adhesions.

Sonography and MRI are helpful in evaluating uterus and vagina. Clinicians give different opinions about the treatment of an obstructive uterus. Some of them recommended hysterectomy ${ }^{77}$ but in contrast, some others reported creation of an epithelialized endocervix and vagina. ${ }^{78,79}$ Thijssen reported a successful pregnancy after a zygote intrafallopian tube transfer in a patient with cervical agenesis. ${ }^{80}$

Surgically, cervical agenesis has historically been treated through hysterectomy (removal of the uterus) to relieve symptoms caused by hematocolpos (the accumulation of menstrual fluid in the vagina). Other surgical methods of management involve the creation of an anastomotic connection between the uterus and vagina by neovaginoplasty or recanalization of the cervix. Outcomes in these cases are generally poor, since the natural functions of the cervix - such as mucus production and providing a barrier against ascending infection-cannot be replicated. Furthermore, the success rate of uterovaginal anastomosis is less 
than $50 \%$ and most patients require multiple surgeries while many develop cervical stenosis. ${ }^{81,82}$ Despite this, several pregnancies have been reported in women with cervical agenesis who underwent surgical treatment. ${ }^{83}$

\section{Cervical Stenosis}

This may result from congenital conditions, due to segmental Müllerian hypoplasia or acquired, due to postoperative conization, infection, neoplasia, or radiation. Cervical stenosis involves internal os and symptoms include amenorrhea, dysmenorrhea, abnormal uterine bleeding, and infertility. Clinical examination and sonography may help the diagnosis (enlarged uterus and presence of liquid inside the uterine cavity). Progressive dilatation of cervical canal is recommended in these cases.

\section{Ovarian Anomalies}

A supernumerary ovary is a rare gynecologic anomaly characterized by the presence of a third ectopic ovary that has no connection with the utero-ovarian ligament and can be located in the pelvis, omentum, mesenterium, or retroperitoneum.

The term accessory ovary is used when the excessive ovarian tissue is placed near a normally placed ovary and is connected to it. Unique ovary or unilateral ovarian absence is also a rare anomaly and present the absence of one ovary, with or without the absence of the corresponding fallopian tube.

Ovarian anomalies are mostly associated with other congenital defects, most frequently genitourinary tract anomalies.

\section{Fallopian Tube Anomalies}

It is a very rare anomaly. A limited number of congenital and acquired defects of the fallopian tubes are described by clinicians. Disease may be asymptomatic or may be linked to infertility. Congenital tubal anomalies include absence of one fallopian tube, accessory ostia, and embryonic cystic remnants of the mesonephric duct (appendix vesiculosa).

Acquired tubal defects are due to inflammatory changes of the fallopian tube tissue due to infection, tuberculosis, endometriosis, pelvic surgery, postabortum, postpartum infections, etc. These inflammatory changes result in proximal or distal tubal obstruction causing infertility.

\section{OrCID}

Orion Gliozheni (i) https://orcid.org/0000-0002-2556-1782

Elko Gliozheni (i) https://orcid.org/0000-0002-1951-9561

\section{References}

1. Sharara Fl. Complete uterine septum with cervical duplication, longitudinal vaginal septum and duplication of a renal collecting system. J Reprod Med 1998;43:1055-1059.

2. Sarris I, Bewley S, Agnihotri S. Oxford specialty training: training in obstetrics and gynaecology (the essential curriculum). embryology of genital tract. Congenital uterine and vaginal anomalies, vol. 26., Oxford: Oxford University Press; 2009. p. 32.

3. Chan YY, Jayaprakasan K, Zamora J, et al. The prevalence of congenital uterine anomalies in unselected and high risk populations: a systematic review. Hum Reprod Update 2011;17(6):761-771. DOI: 10.1093/humupd/dmr028.

4. Saravelos SH, Cocksedge KA, Li TC. Prevalence and diagnosis of congenital uterine anomalies in women with reproductive failure: a critical appraisal. Hum Reprod Update 2008;14(5):415-429. DOI: 10.1093/humupd/dmn018.
5. [Online] Available from: https://courses.washington.edu/conj/bess/ differentiation/differentiation.htm.

6. Hasana DI, Aly Tantawy HI, Shazly SA. Imaging of the uterovaginal anomalies. Egypt J Radiol Nucl Med 2010;41(4):517-523. DOI: 10.1016/j. ejrnm.2010.10.008.

7. Nahum GG. Uterine anomalies, induction of labor, and uterine rupture. Obstet Gynecol 2005;106(5):1150-1152. DOI: 10.1097/01. AOG.0000185308.80753.8f.

8. Achiron R, Tadmor O, Kamar R, et al. Prerupture ultrasound diagnosis of interstitial and rudimentary uterine horn pregnancy in the second trimester: a report of two cases. J Reprod Med 1992;37:89-92.

9. Zaidi J, Carr J. Rupture of pregnant rudimentary uterine horn with fetal salvage. Acta Obstet Gynecol Scand 1994;73(4):359-360. DOI: 10.3109/00016349409015781.

10. Jayasinghe $\mathrm{Y}$, Rane $\mathrm{A}$, Stalewski $\mathrm{H}$, et al. The presentation and early diagnosis of the rudimentary uterine horn. Obstet Gynecol 2005;105(6):1456-1467. DOI: 10.1097/01.AOG.0000161321.94364.56.

11. Burchell RC, Creed F, Rasoulpour M, et al. Vascular anatomy of the human uterus and pregnancy wastage. Br J Obstet Gynaecol 1978;85(9):698-706. DOI: 10.1111/j.1471-0528.1978.tb14950.x.

12. Roddick JWJr, Buckingham JC, Danforth DN. The muscular cervix-a cause of incompetency in pregnancy. Obstet Gynecol 1961;17(5):562565. DOI: 10.1097/00006254-196110000-00005.

13. Blum M. Comparative study of serum CAP activity during pregnancy in malformed and normal uterus. J Perinat Med 1978;6(3):165-168. DOI: 10.1515/jpme.1978.6.3.165.

14. Golan A, Langer R, Wexler S, et al. Cervical cerclage-its role in the pregnant anomalous uterus. Int J Fertil 1990;35:164-170.

15. Abramovici $\mathrm{H}$, Faktor JH, Pascal B. Congenital uterine malformations as indication for cervical suture (cerclage) in habitual abortion and premature delivery. Int J Fertil 1983;28:161-164.

16. Buttram VCJr, Gibbons WE. Müllerian anomalies: a proposed classification. (an analysis of 144 cases). Fertil Steril 1979;32(1):40-46. DOI: 10.1016/S0015-0282(16)44114-2.

17. The American Fertility Society classifications of adnexal adhesions, distal tubal occlusion, tubal occlusion secondary to tubal ligation, tubal pregnancies, müllerian anomalies and intrauterine adhesions. Fertil Steril 1988;49(6):944-955. DOI: 10.1016/S0015-0282(16)59942-7.

18. Grimbizis GF, Gordts S, Di Spiezio Sardo A, et al. The ESHRE/ESGE consensus on the classification of female genital tract congenital anomalies. Hum Reprod 2013;28(8):2032-2044. DOI: 10.1093/humrep/ det098.

19. Heinonen PK. Unicornuate uterus and rudimentary horn. Fertil Steril 1997;68(2):224-230. DOI: 10.1016/S0015-0282(97)81506-3.

20. Hoffman BL, Schorge JO, Schaffer Jl, et al. Williams Gynecology. 2nd ed., New York: McGraw-Hill; 2008. pp. 416-417

21. Kara T, Acu B, Beyhan M, et al. MRI in the diagnosis of Mayer-RokitanskyKuster-Hauser syndrome. Diagn Interv Radiol 2013;19:227-232.

22. Hall-Craggs MA, Williams CE, Pattison SH, et al. Mayer-RokitanskyKuster-Hauser syndrome: diagnosis with MR imaging. Radiology 2013;269(3):787-792. DOI: 10.1148/radiol.13130211.

23. ACOG Committee on Adolescent Health Care. ACOG committee opinion. number 274 , july 2002 . Nonsurgical diagnosis and management of vaginal agenesis. Obstet Gynecol 2002;100:213-216.

24. Roberts CP, Haber MJ, Rock JA. Vaginal creation for Müllerian agenesis. Am J Obstet Gynecol 2001;185(6):1349-1352. DOI: 10.1067/ mob.2001.119075.

25. Croak AJ, Gebhart JB, Klingele CJ, et al. Therapeutic strategies for vAGINAL Müllerian aGENESIS. J Reprod Med 2003;48:395-401.

26. Mc Indoe A. The treatment of congenital absence and obliterative conditions of the vagina. Br J Plast Surg 1950;2:254-267.

27. Brännström $M$, Johannesson $L$, Bokström $H$, et al. Livebirth after uterus transplantation. Lancet 2015;385(9968):607-616. DOI: 10.1016/ S0140-6736(14)61728-1.

28. Johannesson L, Kvarnström N, Mölne J, et al. Uterus transplantation trial: 1-year outcome. Fertil Steril 2015;103(1):199-204. DOI: 10.1016/j. fertnstert.2014.09.024. 
29. Zanetti E, Ferrari LR, Rossi G. Classification and radiographic features of uterine malformations: HSG study. Br J Radiol 1978;51(603):161-170. DOI: 10.1259/0007-1285-51-603-161.

30. Heinonen PK. Clinical implications of the unicornuate uterus with rudimentary horn. Int J Gynecol Obstet 1983;21(2):145-150. DOI: 10.1016/0020-7292(83)90052-8.

31. Fedele L, Zamberletti $D$, Vercellini $P$, et al. Reproductive performance of women with unicornuate uterus. Fertil Steril 1987;47(3):416-419. DOI: 10.1016/S0015-0282(16)59047-5.

32. Akar ME, Bayar D, Yildiz S, et al. Reproductive outcome of women with unicornuate uterus. Aust N Z J Obstet Gynaecol 2005;45(2):148-150. DOI: 10.1111/j.1479-828X.2005.00346.x.

33. Acién P. Reproductive performance of women with uterine malformations. Hum Reprod 1993;8(1):122-126. DOI: 10.1093/ oxfordjournals.humrep.a137860.

34. TheFetus.net. (2007). Uterine malformations. [online] Available from: https://sonoworld.com/fetus/page.aspx?id =2150 [Accessed June, 2018].

35. Medscape. (2016). Imaging in Mullerian Duct Abnormalities. [online] Available from: https://emedicine.medscape.com/article/405335overview [Accessed June, 2018]

36. Radiology Key. (2016). Congenital Uterine Anomalies. [online] Available from: https://radiologykey.com/congenital-uterineanomalies-2/ [Accessed June, 2018].

37. Patel MS, Rotator cuff tear. Radiopaedia. [online] Available from: https://www.radiopaedia.org/cases/rotator-cuff-tear-4. [Accessed June, 2017].

38. Rani A, Kumari M. Shipra. A case of noncommunicating uterine horn containing functional endometrium. Gynecol Obstet (Sunnyvale) 2015;5:320. DOI: 10.4172/2161-0932.

39. Cohen AW, Chhibber G. Obstetric complications of congenital anomalies of the paramesonephric ducts. Semin Reprod Endocrinol 1986;4(01):59-65. DOI: 10.1055/s-2007-1022485.

40. Sen KK, Balasubramaniam D, Kanagaraj V. Magnetic resonance imaging in obstructive Müllerian anomalies. J Hum Reprod Sci 2013;6(2):162-164. DOI: 10.4103/0974-1208.117167.

41. Reichman D, Laufer MR, Robinson BK. Pregnancy outcomes in unicornuate uteri: a review. Fertil Steril 2009;91(5):1886-1894. DOI: 10.1016/j.fertnstert.2008.02.163.

42. Nezhat F, Nezhat C, Bess O, et al. Laparoscopic amputation of noncommunicating rudimentary horn after hysteroscopic diagnosis: a case study. Surg Laparosc Endosc 1994;4:155-156.

43. Wong L, White N, Ramkrishna J, et al. Three-dimensional imaging of the uterus: the value of the coronal plane. World J Radiol 2015;7(12):484-493. DOI: 10.4329/wjr.v7.i12.484.

44. Sakinala K, Anencephaly. Radiopaedia. [online] Available from: https:// radiopaedia.org/cases/anencephaly-2?iframe $=$ true [Accessed June, 2018].

45. Pissat S, Tas B, van Herendael B. Laparoscopic Strassman's metroplasty for bicornuate uterus. Gynecol Surg Endosc Imaging Allied Tech 2009;6(2):463. DOI: 10.1007/s10397-008-0463-1.

46. Hinckley MD, Milki AA. Management of uterus didelphys, obstructed hemivagina and ipsilateral renal agenesis. A case report. J Reprod Med 2003;48:649-651.

47. Coskun A, Okur N, Ozdemir O, et al. Uterus didelphys with an obstructed unilateral vagina by a transverse vaginal septum associated with ipsilateral renal agenesis, duplication of inferior vena cava, high-riding aortic bifurcation and intestinal malrotation: a case report. Fertil Steril 2008;90:2006.e9-11.

48. Growdon WB, Laufer MR. Uterine didelphys with duplicated upper vagina and bilateral lower vaginal agenesis: a novel Müllerian anomaly with options for surgical management. Fertil Steril 2008;89:693-698.

49. Heinonen PK. Clinical implications of the didelphic uterus: long-term follow-up of 49 cases. Eur J Obstet Gynecol Reprod Biol 2000;91: 183-190.
50. Grimbizis GF, Camus M, Tarlatzis BC, et al. Clinical implications of uterine malformations and hysteroscopic treatment results. Hum Reprod Update 2001;7:161-174.

51. Strassman E. Plastic unification of double uterus. Am J Obstet Gynecol 1952;64:25-37.

52. Heinonen PK, Saarikoski S, Pystynen P. Reproductive performance of women with uterine anomalies. An Evaluat 182 Cases Acta Obstet Gynecol Scand 1982;61:157-162.

53. Morgan MA, (2012). A bicornuate uterus. Radiopaedia.org. [online] Available from: https://radiopaedia.org/ [Accessed June, 2018].

54. Matsaseng T, Kruger TF. Laparoscopic Strassman's metroplasty for bicornuate uterus - is it relevant? S Afr J Obstet Gynaecol 2012;18:8587.

55. Sinha R, Mahajan C, Hedge A, et al. Laparoscopic metroplasty for bicornuate uterus. J Minim Invasive Gynecol 2006;13:70-73.

56. Lolis DE, Paschopoulos M, Makrydimas G, et al. Reproductive outcome after strassman metroplasty in women with a bicornuate uterus. J Reprod Med 2005;50:297-301.

57. Heinhonen PK. Complete septate uterus with longitudinal vaginal septum. Fertil Steril 2006;85:700-705.

58. Woelfer B, Salim R, Banerjee S, et al. Reproductive outcome in women with congenital uterine anomalies detected by threedimensional ultrasound screening. Obstet Gynecol 2001;98: 1099-1103.

59. Chervenak FA, Neuwirth RS. Hysteroscopic resection of the uterine septum. Am J Obstet Gynecol 1981;141:351-353.

60. Golan A, Langer R, Bukovsky I, et al. Congenital anomalies of the müllerian system. Fertil Steril 1989;51:747-755.

61. Mollo A, De Franciscis P, Colacurci N, et al. Hysteroscopic resection of the septum improves the pregnancy rate of women with unexplained infertility: a prospective controlled trial. Fertil Steril 2009;91:26282631.

62. Gordts S. New developments in reproductive surgery. Best Pract Res Clin Obstet Gynecol 2013;27:431-440.

63. Kowalik CR, Goddijn M, Emanuel MH, et al. Metroplasty versus expectant management for women with recurrent miscarriage and a septate uterus. Cochrane Database Syst Rev 2011;6: CD008576

64. Behr SC, Courtier JL, Qayyum A. Imaging of müllerian duct anomalies. Radiographics 2012;32:E233-E250.

65. Raga F, Bauset C, Remohi J, et al. Reproductive impact of congenital müllerian anomalies. Hum Reprod 1997;12:2277-2281.

66. Palmer JR, Hatch EE, Rao RS, et al. Infertility among women exposed prenatally to diethylstilbestrol. Am J Epidemiol 2001;154: 316-321.

67. Steinkeler JA, Woodfield CA, Lazarus E, et al. Female infertility: a systematic approach to radiologic imaging and diagnosis. Radiographics 2009;29:1353-1370.

68. Goldberg JM, Falcone T. Effect of diethylstilbestrol on reproductive function. Fertil Steril 1999;72:1-7.

69. IVF-Infertility.com. (2016). Asherman's syndrome. [online] Available from: http://www.ivf-infertility.com/infertility/ashermans.php [Accessed June, 2018] .

70. Silver S, Ginivitra. Asherman's syndrome. 2014

71. Schenker JG, Margalioth EJ. Intrauterine adhesions: an updated appraisal. Fertil Steril 1982;11:593-610.

72. Shaffer W. Role of uterine adhesions in the cause of multiple pregnancy losses. Clin Obstet Gynecol 1986;29:912-924.

73. March CM, Israel R. Gestational outcome following hysteroscopic Iysis of adhesions. Fertil Steril 1981;36:455-459.

74. Valle RF, Sciarra JJ. Intrauterine adhesions: hysteroscopic diagnosis, classification, treatment, and reproductive outcome. Am J Obstet Gynecol 1988;158:1459-1470.

75. Siegler AM, Valle RF. Therapeutic hysteroscopic procedures. Fertil Steril 1988;50:685-701. 
76. Dillon WP, Mudaliar NA, Wingate MB. Congenital atresia of the cervix. Obstet Gynecol 1979;54:126-129.

77. Rock JA, Schlaff WD, Zacur HA, et al. The clinical management of congenital absence of the uterine cervix. Int J Gynaecol Obstet 1984;22:231-235.

78. Niver DH, Barrette G, Jewelewicz R. Congenital atresia of the uterine cervix and vagina. Fertil Steril 1980;33:25-29.

79. Grimbizis GF, Tsalikis T, Mikos T, et al. Successful end-to-end cervico-cervical anastomosis in a patient with congenital cervical fragmentation: case report. Hum Reprod 2004;19: 1204-1210.
80. Thijssen RF, Hollanders JM, Willemsen WN, et al. Successful pregnancy after ZIFT in a patient with congenital cervical atresia. Obstet Gynecol 1990;76:902-904.

81. Sokol Al, Sokol ER. General Gynecology: The Requisites in Obstetrics and Gynecology. Philadelphia: Elsevier; 2013. p. 217.

82. Drutz HP, Herschorn S, Diamant NE. Female Pelvic Medicine and Reconstructive Pelvic Surgery. Berlin/Heidelberg, Germany: Springer Science+Business Media; 2007. p. 54.

83. Arulkumaran $\mathrm{S}$, Lesley R, Aris $\mathrm{P}$, et al., ed. Oxford Desk Reference: Obstetrics and Gynaecology. Oxford: Oxford University Press; 2011. p. 533. 